\title{
Inhibition of Kainate Receptors Reduces the Frequency of Hippocampal Theta Oscillations
}

\author{
John R. Huxter, ${ }^{1,3}$ Larissa E. Zinyuk, ${ }^{1}$ Eva v. L. Roloff, ${ }^{1}$ Vernon R. J. Clarke, ${ }^{1}$ Nigel P. Dolman, ${ }^{2}$ Julia C. A. More, ${ }^{2}$ \\ David E. Jane, ${ }^{2}$ Graham L. Collingridge, ${ }^{1}$ and Robert U. Muller ${ }^{1,4}$ \\ Departments of ${ }^{1}$ Anatomy and ${ }^{2}$ Pharmacology, Medical Research Council Centre for Synaptic Plasticity, University of Bristol, Bristol BS8 1TD, United \\ Kingdom, ${ }^{3}$ Medical Research Council Anatomical Neuropharmacology Unit, University of Oxford, Oxford OX1 3TH, United Kingdom, and ${ }^{4}$ Health Science \\ Center at Brooklyn, State University of New York, Brooklyn, New York 11203
}

We investigated the role of kainate receptors in the generation of theta oscillations using (S)-1-(2-amino-2-carboxyethyl)-3-(2carboxythiophene-3-yl-methyl)pyrimidine-2,4-dione (UBP304), a novel, potent and highly selective antagonist of $\mathrm{GLU}_{\mathrm{K} 5}$-containing kainate receptors. EEG and single-unit recordings were made from the dorsal hippocampus of awake, freely moving rats trained to forage for food. Bilateral intracerebroventricular injections of UBP304 $(2.0 \mu \mathrm{l}$, two times; $2.08 \mathrm{~mm})$ caused a clear $(\sim 25 \%)$ reduction in theta frequency that was dissociable from behavioral effects of the drug. The locations of firing fields of principal cells in the hippocampal formation were generally preserved, but both field firing rates and the precision of field organization decreased. UBP304 lowered the frequency of the theta modulation of hippocampal interneuron discharge, accurately matching the reduced frequency of the theta field oscillation. UBP308 [(R)-1-(2-amino-2-carboxyethyl)-3-(2-carboxythiophene-3-yl-methyl)pyrimidine-2,4-dione], the inactive enantiomer of UBP304, caused none of these effects. Our results suggest that $\mathrm{GLU}_{\mathrm{K} 5}$ receptors have an important role in modulating theta activity. In addition, the effects on cellular responses provide both insight into the mechanisms of theta pacing, and useful information for models of temporal coding.

Key words: hippocampus; electrophysiology; place cells; EEG; GluR5; GLU $\mathrm{K}_{5}$

\section{Introduction}

In awake rats, theta oscillations consist of $5-12 \mathrm{~Hz}$ sine-like waves seen during locomotion and postural changes (Vanderwolf, 1969; Buzsaki, 1989), particularly in the hippocampus, but also in associated limbic structures like the entorhinal cortex (Mitchell and Ranck, 1980; Holsheimer, 1982; Bullock et al., 1990; Pare and Collins, 2000). Possible functional correlates of theta include control of spike timing (Fox et al., 1986), regulation of synaptic plasticity (Skaggs and McNaughton, 1996; Pike et al., 2000), and phase-based encoding of position by place cells (O'Keefe and Recce, 1993; Huxter et al., 2003).

Current flows associated with theta are well understood (Buzsaki et al., 1986; Brankack et al., 1993), but the mechanisms of theta generation and pacing are yet to be determined and are likely complex. The characteristic frequency of theta may reflect cellular mechanisms (Hu et al., 2000), the activity of hippocam-

\footnotetext{
Received March 7, 2006; revised Nov. 17, 2006; accepted Nov. 21, 2006.

This work was supported by the Medical Research Council (United Kingdom), the Wellcome Trust (United Kingdom), and a subcontract from Grant R01 NS20686 from the National Institutes of Health (R.U.M.). The work leading to the synthesis and pharmacological characterization of UBP304 and UBP308 was sponsored by the Biotechnology and Biological Sciences Research Council, United Kingdom. We also thank Dr. Jozsef Csicsvari for helpful comments on this manuscript, Chris Goodall for brain sectioning and cresyl violet staining, Matt Holzer and Julie Milkins for providing electronics and engineering support, Bruno Rivard for developing the microdrives, and Dr. Li Yu for producing proprietary software used for the analysis of data.

Correspondence should be addressed to Dr. John R. Huxter, Medical Research Council Anatomical Neuropharmacology Unit, University of Oxford, Mansfield Road, Oxford OX1 3TH, UK. E-mail: john.huxter@pharm.ox.ac.uk. DOI:10.1523/JNEUROSCI.3954-06.2007

Copyright $\odot 2007$ Society for Neuroscience $\quad$ 0270-6474/07/272212-12\$15.00/0
}

pal rhythm generators (Bragin et al., 1995), or the activity of extrahippocampal structures (Petsche et al., 1962). The synchronicity of theta phase along the septal-temporal extent of the hippocampus (Bullock et al., 1990) implies widely distributed intrahippocampal connections, broad divergence from a rhythm source such as the medial septum/diagonal band of Broca (MSDBB), or both.

Lesion work shows that cholinergic and GABAergic MS-DBB projections to the hippocampus and other limbic areas are essential for normal theta. Because muscarinic receptors are too slow to follow theta (Cole and Nicoll, 1983), any MS-DBB role in pacing theta depends on the GABAergic projections. GABAergic interneurons in the hippocampus form complex inhibitory networks that may also play a major role in theta synchronization (Traub et al., 1989; Gillies et al., 2002). Moreover, this network is reciprocally connected to GABAergic projecting cells of the MSDBB (Toth et al., 1993). Thus, modifying GABAergic cell excitability is expected to alter theta. Specifically, if theta rhythm generation and theta current generation are relatively independent (Buzsaki, 2002), changes of interneuron activity might affect theta frequency but not magnitude.

A possible method of changing theta frequency arises from the preferential occurrence of hippocampal $\mathrm{GLU}_{\mathrm{K} 5}$ kainate receptors on interneurons $\left[\mathrm{GLU}_{\mathrm{K} 5}\right.$, International Union of Basic and Clinical Pharmacology nomenclature for the GluR5 (glutamate receptor 5) subunit]. In juvenile rats, $>80 \%$ of hippocampal cells expressing $\mathrm{GLU}_{\mathrm{K} 5}$ mRNA are GABAergic (Paternain et al., 2000). 
Therefore, modifying $\mathrm{GLU}_{\mathrm{K} 5}$ receptor activity may selectively modify theta frequency. The recent development of selective antagonists for kainate receptor subtypes provides an opportunity to determine the role of interneurons expressing particular kainate receptors in the generation and pacing of theta.

To this end, we characterized, for the first time, the effects of inhibiting a specific kainate receptor subtype on theta oscillations and cell firing in awake, freely moving rats. We made intracerebroventricular injections of (S)-1-(2-amino-2-carboxyethyl)-3(2-carboxythiophene-3-yl-methyl)pyrimidine-2,4-dione (UBP304), a novel and highly specific antagonist of $\mathrm{GLU}_{\mathrm{K} 5}$ receptors (Dolman et al., 2006); additional experiments with hippocampal slices demonstrated the specificity and potency of the compound. We found that UBP304 caused reliable, transient theta frequency reductions of $\sim 1.5 \mathrm{~Hz}$ at maximum effect. Food foraging behavior was not greatly affected but significant changes were seen in the activity of place cells and interneurons.

\section{Materials and Methods}

\section{Drugs used}

UBP304 is a recent member of a series of compounds that are specific, potent competitive antagonists of $\mathrm{GLU}_{\mathrm{K} 5}$-containing kainate receptors (More et al., 2004; Dolman et al., 2006). (R)-1-(2-Amino-2carboxyethyl)-3-(2-carboxythiophene-3-yl-methyl)pyrimidine-2,4-dione (UBP308) is the $R$-enantiomer of UBP304 and was synthesized for use as a control in these experiments. Details of the chemical synthesis and pharmacological characterization of UBP304 and UBP308 have been reported previously (Dolman et al., 2006).

\section{Hippocampal slice electrophysiology}

Wistar rats were killed and decapitated at postnatal day 14 in accordance with United Kingdom Home Office regulations. The brain was placed in ice-chilled artificial CSF ( $\mathrm{aCSF}$ ) composed of the following (in mM): 124 $\mathrm{NaCl}, 3 \mathrm{KCl}, 26 \mathrm{NaHCO}_{3}, 2 \mathrm{CaCl}_{2}, 1 \mathrm{MgSO}_{4}, 10 \mathrm{D}$-glucose, and 1.25 $\mathrm{NaH}_{2} \mathrm{PO}_{4}$ saturated with $95 \% \mathrm{O}_{2}$ and $5 \% \mathrm{CO}_{2}$. Parasagittal hippocampal slices ( $400 \mu \mathrm{m}$ thick) were cut on a vibrotome and area CA3 was removed. After equilibration in a holding chamber for at least an hour at $\sim 22^{\circ} \mathrm{C}$, slices were put on a nylon mesh in an interface recording chamber at $29-31^{\circ} \mathrm{C}$ and perfused with aCSF $\left(1.8-2.2 \mathrm{ml} \mathrm{min}^{-1}\right)$. Recordings were made with an Axoclamp 2C amplifier (Molecular Devices, Foster City, CA). Field EPSPs (fEPSPs) were recorded with glass microelectrodes filled with $4 \mathrm{~m} \mathrm{NaCl}$ inserted in stratum radiatum of area CA1. Intracellular recordings from the cell body of CA1 pyramidal neurons were made with $2 \mathrm{M}$ potassium methylsulfate-filled sharp microelectrodes (40-90 M $\Omega$ resistance). Neurons were used only if (1) the resting membrane potential was more negative than $-60 \mathrm{mV}$, (2) the resting input resistance was in the range of $30-55 \mathrm{M} \Omega$, (3) the action potential amplitude was $>80 \mathrm{mV}$, and (4) spike frequency adaptation occurred during depolarizing current steps.

AMPA receptor-mediated fEPSPs were induced using single shock stimulation of Schaffer collateral-commissural fibers at $30 \mathrm{~s}$ intervals with bipolar nickel-chromium electrodes. The response of AMPA receptor-mediated synaptic transmission to UBP304 was determined by the ability of increasing concentrations of the compound to depress the evoked fEPSPs. Based on these results, we then tested the ability of UBP304 and UBP308, at doses subthreshold for effects on AMPA receptors, to antagonize (RS)-2-amino-3-(3-hydroxy-5-tert-butylisoxazol-4yl)propanoic acid (ATPA)-induced depression of fEPSPs. ATPA is a selective $\mathrm{GLU}_{\mathrm{K} 5}$ receptor agonist whose depressant effects are age dependent and undergo pronounced desensitization to repeated applications (Clarke and Collingridge, 2002). Therefore, one-half of the experiments were performed by applying ATPA first in the absence and then the presence of antagonist, and one-half in the reverse order. Values of fEPSPs and IPSPs were based on averages of the two sets of experiments.

After a sustained period of stable recording, NMDA receptormediated fEPSPs were obtained using bath application of 1-(4-aminophenyl)-3-methylcarbamyl-4-methyl-7,8-methylenedioxy-3,4-
dihydro-5H-2,3-benzodiazepine (GYKI53655) (50 $\mu \mathrm{M})$, picrotoxin (50 $\mu \mathrm{M})$, and (2S)-3-[[(1S)-1-(3,4-dichlorophenyl)ethyl] amino-2-hydroxypropyl] (phenylmethyl)phosphinic acid (CGP55845A) $(10 \mu \mathrm{M})$ to block AMPA, $\mathrm{GABA}_{\mathrm{A}}$, and $\mathrm{GABA}_{\mathrm{B}}$ receptor-mediated potentials, respectively. The concentration of $\mathrm{Mg}^{2+}$ in the perfusate was also lowered from $2 \mathrm{~mm}$ to $100 \mu \mathrm{M}$ to facilitate low-frequency activation of NMDA receptors (Coan and Collingridge, 1985). Responses were confirmed as being mediated by NMDA receptors by the application of D-(-)-2-amino-5phosphonopentanoic acid (AP5), which eliminated the remaining evoked response.

Monosynaptic GABAergic responses were evoked with bipolar stimulating electrodes in stratum radiatum close $(<0.5 \mathrm{~mm})$ to the recording site (Davies et al., 1990). The NMDA receptor-mediated component of excitatory synaptic transmission was blocked with $50 \mu \mathrm{M} \mathrm{AP5}$, and the AMPA receptor-mediated component was blocked with $50 \mu \mathrm{M}$ GYKI53655. Input resistance was monitored by passing square current pulses (0.2-0.4 nA amplitude; $500 \mathrm{~ms}$ ) that hyperpolarized the cell from its resting potential.

Compounds were administered through the superfusing medium for sufficient time to allow equilibration. For intracellular experiments, drug-induced changes in membrane potential were compensated by injecting current to maintain the original resting potential so that IPSP and input resistance comparisons were made at a fixed voltage. Extracellular and intracellular data were normalized to a 20 or $10 \mathrm{~min}$ baseline, respectively. Data were collected and analyzed using LTP software (Anderson and Collingridge, 2001). Statistical significance was assessed using paired Student's $t$ tests.

AP5, ATPA, CGP55845A, and picrotoxin were purchased from Tocris Cookson (Avonmouth, UK). GYKI53655 (LY300168) was a kind gift from Dr. D. Bleakman (Eli Lilly, Indianapolis, IN). AP5 and ATPA were dissolved in equimolar NaOH. CGP55845A, GYKI53655, and picrotoxin were dissolved in DMSO. Stock solutions were stored frozen and diluted 1000 -fold to test concentration, with the exception of picrotoxin, which was diluted 100-fold.

\section{Methods for freely moving rats}

Subjects. Sixteen male Long-Evans rats (Harlan, Bicester, UK) weighing between 350 and $450 \mathrm{~g}$ at the start of the experiment were individually housed and kept on a $12 \mathrm{~h}$ light/dark cycle with lights on at 8:00 A.M. Seven days after surgery, rats were reduced to $85 \%$ of their preoperative weight and kept on a restricted diet allowing $5 \mathrm{~g}$ of weight gain per week. Water was always available ad libitum.

Surgery. Rats were anesthetized with a mixture of isoflurane (3\%), oxygen $(1.5 \mathrm{~L} / \mathrm{min})$, and nitrous oxide $(1.5 \mathrm{~L} / \mathrm{min})$. Buprenorphine hydrochloride $(0.07 \mathrm{ml}$, i.m.; $0.3 \mathrm{mg} / \mathrm{ml})$ was given for postoperative analgesia and the antibiotic enroflaxin $(0.1 \mathrm{ml}$, s.c.; $25 \mathrm{mg} / \mathrm{ml})$ was given prophylactically. Recordings were made with a four tetrode implant with the tips initially positioned above the dorsal hippocampus, $3.8 \mathrm{~mm}$ posterior and $3.0 \mathrm{~mm}$ lateral to bregma and $1.5 \mathrm{~mm}$ below brain surface. Tetrodes were made from four $25 \mu \mathrm{m}$ diameter HM-L-coated $90 \%$ platinum-10\% iridium wires (California Fine Wire, Grover Beach, CA), twisted together and blunt cut; each tetrode could be moved independently. For intracerebroventricular drug administration, 26 gauge stainless-steel cannulas (Plastics One, Roanoke, VA) were put bilaterally into the lateral ventricles $(1.0 \mathrm{~mm}$ posterior and $\pm 1.9 \mathrm{~mm}$ lateral to bregma and $3.5 \mathrm{~mm}$ below brain surface, angled to the posterior at $30^{\circ}$ ). The implants and cannulas were secured to stainless-steel skull screws with gentamicin-impregnated bone cement (Palacose R-40; ScheringPlough, Brussels, Belgium).

Behavioral arenas and tasks. Training and recording sessions were done in one of two experimental arenas centered in a $2.0 \times 2.5 \mathrm{~m}$ room. One was a $76 \mathrm{~cm}$ diameter, $51 \mathrm{~cm}$ high gray cylinder with a white cue card that covered $45^{\circ}$ of the interior surface. The cylinder was put on a piece of gray photographic paper. The cylinder was surrounded by a black circular curtain. Eight $25 \mathrm{~W}$ bulbs mounted in a circle on a $1 \mathrm{~m}$ disk centered $232 \mathrm{~cm}$ over the arena were controlled with a variac. A video camera mounted vertically at the disk center (CCD-TR728E; Sony, Tokyo, Japan) was used to track the rat's position. A pellet feeder above the disk dropped $25 \mathrm{mg}$ food pellets (Bio-Serv, Frenchtown, NJ) to random loca- 
tions in the cylinder at a rate of approximately four per minute. Pellet delivery was accompanied by an audible tone. The food-deprived rats spent most of their time finding pellets and then eating them. In this way, it was possible to measure firing rate as a function of position everywhere in the cylinder.

The second apparatus was a version of the cylinder modified to function as a $10-\mathrm{cm}$-wide circular track by inserting at the cylinder center a 65 $\mathrm{cm}$ diameter, $64 \mathrm{~cm}$ high black circular cone. The rat could obtain a 25 $\mathrm{mg}$ food pellet by running away from a feeding cup around the circle in either direction back to the feeding cup. On return, a pellet was delivered into the cup via a tube fitted between the feeder and the cup. The food cup was centered on the clockwise edge of the white card.

Electrophysiological recordings. Signals from the 16 recording channels of the implant were amplified 1 [SCAP] $\times$ on the head and led via a cable to a commutator (Dragonfly, Ridgeley, WV) whose fixed end went to a distribution panel. Each channel was split in two and separately amplified and filtered. The 16 single-unit channels were amplified 10,000$50,000 \times$ and bandpass filtered between 300 and $6000 \mathrm{~Hz}$. The 16 EEG signals were amplified $5000 \times$ and bandpass filtered between 1 and $50 \mathrm{~Hz}$. One of the skull screws over the left cortical hemisphere served as the EEG reference. After conditioning, all 32 signals were brought to a 12 bit analog-to-digital converter; each single unit channel was digitized at 30 $\mathrm{kHz}$ and each EEG channel at $1.875 \mathrm{kHz}$. An event was stored on the computer each time any of the four wires of a tetrode exceeded a threshold set between 50 and $100 \mu \mathrm{V}$; each event consisted of 32 samples for each wire so that the duration was just $>1 \mathrm{~ms}$. EEG channel data were recorded continuously. The data acquisition system was controlled by Cheetah software (Neuralynx, Tucson, AZ).

Rats were tracked by digitizing at $25 \mathrm{~Hz}$ the location of two red lightemitting diodes mounted on the implant $55 \mathrm{~mm}$ above the head and 7.5 $\mathrm{mm}$ behind the rat's eyes. The initial linear resolution for tracking was 1.7 $\mathrm{mm} /$ pixel; for analysis, the resolution was reduced to $33 \mathrm{~mm} /$ pixel.

Training and cell screening. Seven rats were trained to forage in the cylinder, and five other rats were trained to run in the circular track. Rats were trained $5 \mathrm{~d}$ per week until the appropriate behavior was consistent. During training, the tetrodes were lowered 30-60 $\mu \mathrm{m}$ each day until their tips could record from cells in the pyramidal cell layer of CA1 and CA3 and the granule cell layer of the dentate gyrus (DG); this process took between 1 and 3 weeks for a rat. Correct tetrode positioning was judged by prominent theta activity in EEG recordings, background theta frequency modulated interneuron discharge, and putative pyramidal cell complex spike firing. Recordings from superficial tetrodes were attributed to the CA1 pyramidal layer. Recordings from deeper tetrodes detecting higher amplitude inverted theta oscillations (relative to CA1) were attributed to dentate gyrus (medial placements) or CA3 (lateral placements). Final estimates of electrode tip positions were obtained from postmortem histology. Formal testing did not start until we were confident that at least five cells could be simultaneously recorded.

Drug tests. Series of 16 min recording sessions were used to determine the effects of $\mathrm{GLU}_{\mathrm{K} 5}$ receptor antagonism. Between sessions, rats were disconnected and removed from the recording room, and the paper under the arena was changed. Drug-free baseline measures were made for each rat's behavior, EEG signals and single-cell activity during a predrug session, after which the rat was briefly returned to its home cage. Approximately $10 \mathrm{~min}$ later, it was gently wrapped and dummy stylets removed from the cannulas so that $2.0 \mu \mathrm{l}$ of UBP304 $(2.08 \mathrm{~mm})$ could be simultaneously injected into each ventricle over $\sim 10 \mathrm{~min}$ with infusion pumps. After injection, the stylets were left in place for $1 \mathrm{~min}$, the dummy injectors replaced, and the rat returned to its cage. Rats were observed for 5-10 min after injection for abnormal behavior including seizure activity but none was seen. At the end of the observation period, a series of 16 min postdrug sessions were conducted. All testing was done the first time a rat was exposed to UBP304.

To rule out the possibility that any effects were attributable to restraint or injection per se, some rats were also injected with UBP308, the inactive $R$-enantiomer of UBP304, on a separate day of testing. The order in which UBP304 and UBP308 were administered varied randomly from rat to rat. The lack of observable changes after UBP308 injections also rules out $\mathrm{pH}$ or osmolarity changes of the CSF as possible pharmacodynamic mechanisms.

Four of the 16 rats were used specifically to test the effect of two different doses of UBP304 (2.08 and $1.04 \mathrm{~mm}$ ) on theta oscillations, with aCSF used as the "zero concentration" control instead of UBP308. The doses were administered in pseudorandom order on separate days. These rats were not used for any of the other analyses.

Finally, to test whether potential changes in theta frequency can be attributed to UBP304-induced decreases of body temperature (Whishaw and Vanderwolf, 1971), two rats were given a second dose of the drug (2.0 $\mu \mathrm{l} ; 2.08 \mathrm{~mm}$ ) and rectal temperature was recorded at regular intervals over $\sim 30 \mathrm{~min}$. Only small variations in temperature were seen, an increase of $\sim 1^{\circ} \mathrm{C}$ in one animal and a similar decrease in the second animal. We conclude that any ability of UBP304 to alter theta oscillations is not temperature induced.

Unit isolation and characterization. Separation of stored events into action potential time series generated by single cells was done by clustercutting (Gray et al., 1995) with Offline Sorter (Plexon, Dallas, TX). The software generates three-dimensional displays of spike parameter points that were rotated to produce a view in which a set of points is isolated on all sides. This view was then projected onto a two-dimensional display and a boundary drawn around the putative cluster. This process was repeated, with occasional changes of parameters, until no other separable clusters were visible. Usually three to six clusters (cells) could be isolated per tetrode, although some tetrodes had higher yields.

Isolated cells were classified according to histologically confirmed tetrode location, temporal firing pattern, and waveform shape. Cells with broad (initial negative phase, $>250 \mu$ s) action potentials that fired spike bursts, had a low ( $<5$ spikes/s) overall firing rate, and showed pauses $>0.5$ s were considered pyramidal cells (CA1 or CA3), granule cells (dentate gyrus), or mossy cells [polymorph (PM) layer]. Cells with short (initial negative phase, $<250 \mu$ s) action potentials that fired only simple spikes were considered interneurons. The presence of burst spiking in a given cell was verified by the presence of a short-interval peak in the interspike interval histogram. Cells that did not fall into either class were eliminated from additional consideration.

Data analysis. Instantaneous running speed was calculated as the distance moved in $0.4 \mathrm{~s}$ nonoverlapping intervals. Spikes and EEG values occurring during a given interval were assigned the same running speed. The mean running speed for a session was the average for all intervals in which the running speed was $>5 \mathrm{~cm} / \mathrm{s}$. All measures of single-cell activity were restricted to intervals during which the rat was moving $>5 \mathrm{~cm} / \mathrm{s}$.

Spike activity was routinely characterized in several ways including generation of autocorrelations and interspike interval distributions. Visualizing spatial firing patterns was done in two steps. First, the positional firing rate distribution was calculated by dividing the number of spikes in a pixel by the total time the rat's head was detected in that pixel. Second, a false color map was generated such that the rate in each pixel was coded in the order yellow, orange, red, green, blue, purple (Muller et al., 1987). Yellow was used for pixels in which the rate was exactly zero, a choice that emphasizes the extreme spatial specificity of place cell discharge. The positional firing rate distribution was also used to calculate the following: (1) grand average firing rate, the total number of spikes divided by the session duration; (2) peak firing rate, the rate in the median pixel of the highest rate (purple) category; (3) coherence, a 2E nearest neighbor autocorrelation that estimates the local orderliness of positional firing patterns; numerically, it is the z-transform of the correlation between the rate in a pixel and the average rate in its eight nearest neighbors; according to previous work by Rotenberg et al. (1996, 2000), cells with coherence values $>0.3$ are taken by trained observers to be place cells; (4) spatial information content (Skaggs et al., 1993), which measures the extent to which uncertainty of the rat's position is reduced by a single spike. Information content (in bits) is $\Sigma\left[P_{i} \times\left(R_{i} / R_{\mathrm{o}}\right) \times \log _{2}\left(R_{i} / R_{\mathrm{o}}\right)\right]$, where $P_{i}$ is the probability of occupancy in pixel $i, R_{i}$ is the firing rate in that pixel, and $R_{\mathrm{o}}$ is the overall firing rate for the cell.

The power spectrum of the EEG was characterized in the range of $0-50$ $\mathrm{Hz}$ using 1024 frequency bins (NeuroExplorer, Littleton, MA). The power spectral density curve was smoothed with a 20 bin running average. Theta frequency was taken as the largest peak in the $5-10 \mathrm{~Hz}$ range 
and theta power as the height of the peak. We eliminated cases in which the power spectrum was not clearly unimodal in the theta range. The rhythmic firing frequency (RFF) of interneurons was also estimated with power spectral density analysis using similar parameters. RFF can be thought of as the periodicity of higher cell firing probability, as opposed to the overall firing rate.

The preferred theta firing phase for interneurons was calculated relative to the EEG from the CA1 pyramidal cell layer. Off-line, the raw EEG was passed through a bidirectional digital Butterworth filter (high-pass, 2 $\mathrm{Hz}$ ) and averaged with a $21 \mathrm{~ms}$ sliding window to remove high-frequency components. A sine wave in the theta range $(5-12 \mathrm{~Hz})$ was aligned on each negative-going deflection in the filtered EEG, and the goodness-offit (mean square error, $<0.6$ ) was used to detect the presence of theta. The phase of a spike in degrees is the ratio of the interval between the previous zero crossing and the spike to the interval between previous and next zero crossings (Huxter et al., 2003).

The effects of UBP304 and UBP308 on pyramidal cell activity were assessed with a mixed design ANOVA using "drug" (UBP304 vs UBP308) as the between-subjects measure, and "time" (pre- vs 30 min post-drug injection) as the repeated measure. We compared predrug and $30 \mathrm{~min}$ postdrug values for overall firing rate, peak firing rate, coherence, and spatial information content. Cells were excluded if their overall firing rate was $<0.05 \mathrm{~Hz}$ in either the predrug or postdrug session. A separate analysis was done for cells from CA1, CA3, and DG. Similarly, the effects of UBP304 and UBP308 were determined for interneurons on the following values: overall firing rate, the frequency of the theta power spectrum peak, and the amplitude of the theta power spectrum peak and firing phase. In addition, the peak theta frequency was compared with the simultaneously measured peak of the CA1 EEG power spectrum. To properly compare interneuron and theta rhythmicity, the EEG and cell data were both restricted to intervals when running speed was $>5 \mathrm{~cm} / \mathrm{s}$. For some analyses based on small samples of EEG data, the width of detected theta cycles was used as an alternative measure of theta frequency.

Histology. Rats were killed by sodium pentobarbital overdose and perfused transcardially with saline followed by $4 \%$ paraformaldehyde (PFA) in phosphate buffer. Brains were removed, stored in $4 \%$ PFA, and transferred to $30 \%$ sucrose solution for $\sim 48 \mathrm{~h}$ before sectioning. Using a microtome, $30 \mu \mathrm{m}$ coronal and sagittal sections were taken from the right and left hemispheres, respectively, and stained with cresyl violet. Coronal sections were used to confirm electrode placement in the hippocampus; sagittal sections were used to confirm the position of the cannulas in the lateral ventricles.

\section{Results}

\section{Slice recordings}

We assessed the effectiveness of UBP304 and UBP308 as antagonists of $\mathrm{GLU}_{\mathrm{K} 5}$-containing kainate receptors in the CA1 region of the hippocampus by measuring their ability to block the effects of ATPA, a GLU $\mathrm{K}_{5}$ selective agonist. To establish selective concentration levels, we first determined the effectiveness of UBP304 and UBP308 as AMPA receptor antagonists in the hippocampus by constructing sequential concentration-response curves (Fig. $1 A$, left). As shown in Figure $1 A$, right, UBP304 was a weak antagonist that depressed AMPA receptor-mediated synaptic transmission with an $\mathrm{IC}_{50}$ of $37 \mu \mathrm{M}(n=3)$ and UBP308 was weaker still. At a concentration of $3 \mu \mathrm{M}$, neither UBP304 nor UBP308 has a significant effect on low-frequency evoked AMPA receptor-mediated synaptic transmission (depressions of $3 \pm 4$ and $2 \pm 2 \%$, respectively; $n=3$ ). We therefore tested the ability of this concentration of both compounds to inhibit fEPSP depression caused by $1 \mu \mathrm{M}$ ATPA (Fig. $1 B$ ) via activation of GLU $\mathrm{K}_{5}$ receptors on the presynaptic terminals of Schaffer collateralcommissural fibers (Vignes et al., 1998). At $3 \mu \mathrm{M}$, UBP304 antagonized the effects of ATPA by $94 \pm 5 \%(n=4$; $p<0.05)$. In contrast, UBP308 had no significant effect on the effects of ATPA $(n=4 ; p>0.05)$. As shown in Figure $1 C$, at a dose of $100 \mu \mathrm{M}$, neither UBP304 nor UBP308 has any effect on low-frequency evoked NMDA receptor-mediated synaptic transmission (depression of $2 \pm 10$ and $5 \pm 4 \%$, respectively; $n=3$ ). Finally, we evaluated the ability of UBP304 and UBP308 to reverse ATPAmediated depression of monosynaptically evoked IPSPs (Fig. $1 D$ ) caused by activation of $\mathrm{GLU}_{\mathrm{K} 5}$ receptors on inhibitory interneurons (Clarke et al., 1997); this was done after blockade of both AMPA and NMDA receptor-mediated components of glutamatergic transmission. At $3 \mu \mathrm{M}, \mathrm{UBP} 304$ caused a strong $(92 \pm 4 \%)$ antagonism of this effect $(n=4 ; p<0.05)$, whereas UBP308 had no significant effect $(n=4 ; p>0.05)$.

In conclusion, UBP304 is a potent antagonist of $\mathrm{GLU}_{\mathrm{K} 5^{-}}$ containing kainate receptor-mediated effects in the hippocampus, whereas UBP308 is inactive. In comparison, these compounds are very weak AMPA receptor antagonists and are inactive at NMDA receptors.

\section{In vivo recordings}

Simultaneous EEG and single-unit recordings were made from 12 rats before and after UBP304 administration. One rat ceased to run after the UBP304 injection and was excluded from the sample. Six rats were also injected with UBP308. Tetrodes were implanted in CA1 in all rats, in dentate gyrus in five, and in CA3 in four. Tetrode positions were confirmed electrophysiologically and with postmortem histology.

\section{$\mathrm{GLU}_{\mathrm{K} 5}$ blockade reduces the frequency of theta but does not affect its power}

The primary effect of UBP304 administration is shown in the representative power spectral density plot of Figure $2 \mathrm{~A}$. In this example, the $\sim 1.5 \mathrm{~Hz}$ shift in the peak of the power spectrum is evident. Raw data from another rat is shown in the $3 \mathrm{~s}$ EEG records of Figure $2 B$, which were selected for the presence of clear theta activity. In the top predrug panel, there are 26 negative theta peaks for an average frequency of $8.7 \mathrm{~Hz}$, whereas in the bottom 30 min postdrug panel, there are only 18 peaks for an average frequency of $6.0 \mathrm{~Hz}$. Inspection of Figure $2 B$ strongly suggests that this $31 \%$ frequency decrease was unaccompanied by a change in theta power.

Sequential recordings after UBP304 injection allowed us to follow the time course of the drug effect, as shown in Figure 2C, where average peak frequency and average peak power in CA1 and the DG are plotted for six sessions. The maximum frequency decrease occurred during the first session, begun at $t=8 \mathrm{~min}$ after injection. The frequency then gradually increased and was indistinguishable from its control value at $t=120$ after injection. Theta power did not change systematically during the observation time (Fig. $2 C$, right). In contrast to the ability of UBP304 to lower theta frequency, UBP308 had no systematic effect on theta frequency or power over an 80 min time course, as shown in Figure 2, $D$ and $E$. A paired $t$ test found that $30 \mathrm{~min}$ after injection, UBP304 caused a significant reduction in theta frequency $\left(t_{(1,9)}=-6.08 ; p<0.001\right)$ but had no effect on theta power $\left(t_{(1,9)}=-0.33 ; p=0.75\right)$, whereas UBP308 caused no significant reduction in either theta frequency $\left(t_{(1,5)}=-0.97 ; p=0.38\right)$ or power $\left(t_{(1,5)}=-1.42 ; p=0.22\right)$.

To determine dose dependence, four additional rats were given the full dose (2.08 mM) of UBP304, a half-dose (1.04 mM), and an additional injection of vehicle (aCSF) as a zero concentration control; injections at each dose were given on separate days. The results are presented in Figure $3, A$ and $B$. A repeatedmeasures ANOVA determined that there was a significant effect of time (pre-post, $F_{(1,9)}=45.94 ; p<0.0001$ ), and a strong inter- 
action of time with dose $\left(F_{(2,9)}=10.70\right.$; $p<0.01)$. One-tailed paired $t$ tests revealed a significant reduction in theta frequency at the full dose of UBP304 $\left(t_{(1,3)}=\right.$ $-7.94 ; p<0.01)$, and at the half dose $\left(t_{(1,3)}=-3.02 ; p<0.05\right)$ but not for aCSF $\left(t_{(1,3)}=-1.13 ; p=0.34\right)$. There was a strong linear correlation between dose of UBP304 and the percentage reduction in theta frequency after injection $\left(R^{2}=0.69\right.$; $\left.F_{(1,10)}=21.84 ; p<0.001\right)$. In contrast, there was no overall effect of UBP304 concentration on theta power $\left(F_{(2,8)}=0.65\right.$; $p=0.55$ ), no overall effect of time (prepost, $\left.F_{(1,8)}=3.26 ; p=0.11\right)$, and no dosetime interaction $\left(F_{(2,8)}=0.46 ; p=0.64\right)$. Furthermore, there was no correlation between UBP304 dose and the percentage reduction in theta power $\left(R^{2}=0.15\right.$; $\left.F_{(1,10)}=1.83 ; p=0.21\right)$.

\section{Drug effects are not produced by changes in running speed}

Next, we asked whether the main EEG effect of blocking kainate receptors could be secondary to slower locomotion. An initial analysis suggests this might be the case: reductions of theta frequency after UBP304 injection (Fig. 3C, left) are paralleled by reductions of running speed (Fig. $3 D$, left). Analysis of similar results after UBP308 injections indicates, however, that the UBP304-induced decreases of running speed and theta frequency may be independent effects. Thus, for UBP308, there is little trend for theta frequency to decrease (Fig. 3C, right) in the face of marked slowing of running speed during successive sessions (Fig. 3D, right).

To properly determine whether the effect of UBP304 on theta frequency is secondary to changes in locomotion, we determined the normal relationship between running speed and theta frequency. Figure $3 E$ shows the instantaneous running speed distribution for all rats combined, with a "hump" near the mean of $18.5 \mathrm{~cm} / \mathrm{s}$, which reflects typical locomotion on the random foraging task. Speeds $>50 \mathrm{~cm} / \mathrm{s}$ were unusual except on the circular track. Figure $3 F$ shows the relationship between running speed and CA1 theta frequency for predrug trials. The data were fit with the following $\log$ function: theta frequency $=$ $7.83+0.20 \times \log _{\mathrm{e}}$ (running speed $)\left(R^{2}=\right.$ $\left.0.17 ; F_{(1,215)}=43.81 ; p<0.0001\right)$. Based on the regression equation, the reduction in mean running speed from 26.06 to $18.22 \mathrm{~cm} / \mathrm{s}$ immediately after administration of UBP304 would be expected to produce only a $0.07 \mathrm{~Hz}$ reduction in theta frequency, much less than the observed reduction.

A "speed-clamped" analysis (Fig. $3 G$ ) provides stronger evi-
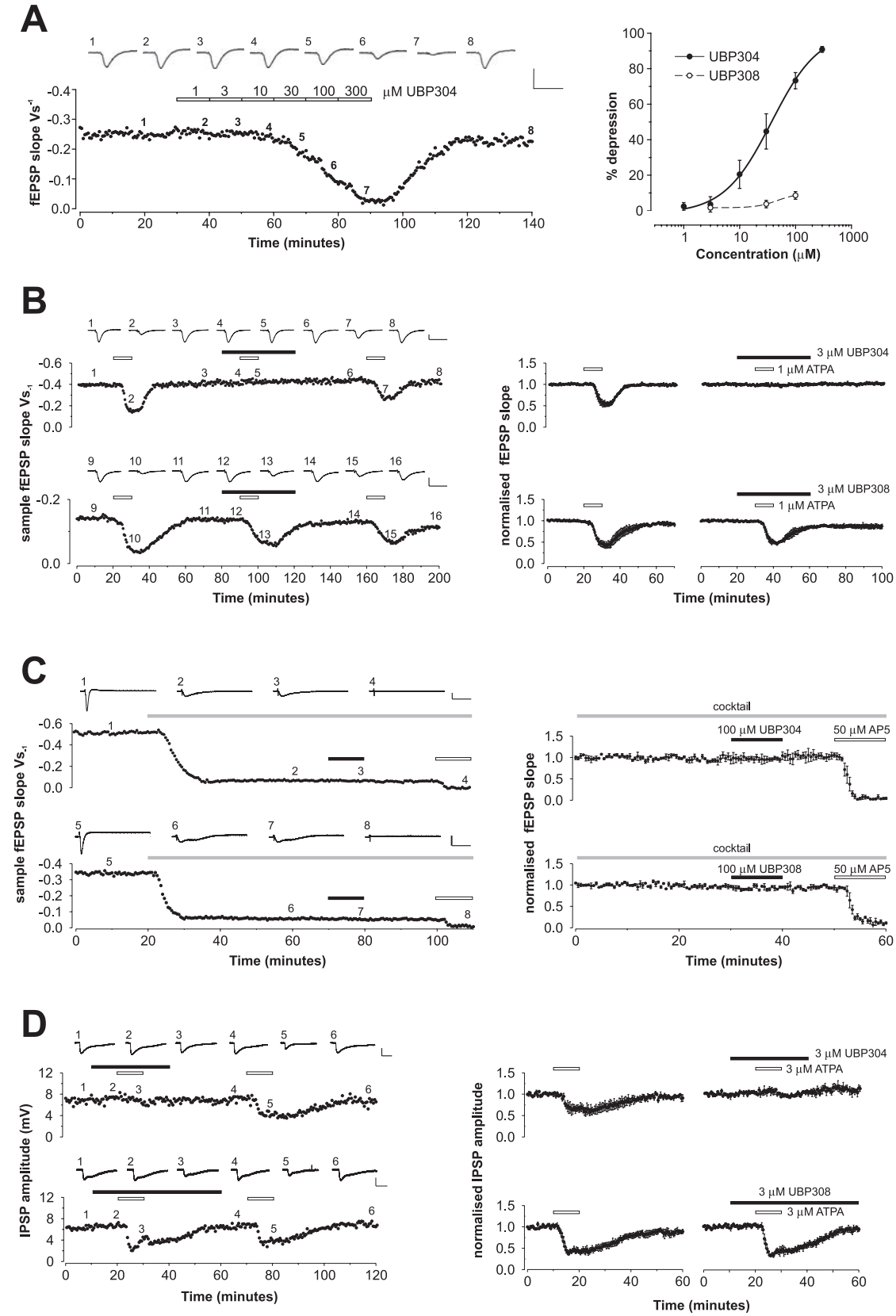

Figure 1. Characterization of UBP304 and UBP308 effects in the CA1 region of the hippocampus. A, Left, fEPSP depression with increasing doses of UBP304. Right, fEPSP depression as a function of UBP304 and UBP308 concentration (average of 3 replications). Each line is fitted to the Hill equation; for UBP304, the Hill coefficient is 1.02 , and the $\mathrm{IC}_{50}$ is $37 \mu \mathrm{m}$. Error bars indicate SEM. $\boldsymbol{B}$, Left, Top curves, At a UBP304 concentration $(3 \mu \mathrm{m})$ that does not affect AMPA receptor-mediated transmission, the depressant effect of ATPA $(1 \mu \mathrm{M})$ on fEPSPs is completely antagonized. The $3 \mu \mathrm{m}$ concentration of the inactive enantiomer UBP308 does not relieve the depressant effect of ATPA. Right, Top curves, Normalized decreases of fEPSP slope attributable to ATPA and elimination of the reduction in the presence of UBP304. Right, Bottom, With the same protocol, UBP308 does not modify the reduction of fEPSP slope. C, Neither UBP304 nor UBP308 (100 $\mu \mathrm{M}$ ) has any effect on NMDA receptor-mediated transmission recorded in the presence of a mixture of GYKI53655 (50 $\mu \mathrm{M}$ ), picrotoxin (50 $\mu \mathrm{M})$, and (GP55845A $(1 \mu \mathrm{M})$ to block AMPA, GABA $A^{\prime}$ and $\mathrm{GABA}_{B}$ receptor-mediated transmission, respectively. Low $\mathrm{Mg}^{2+}$ was used to enhance the size of the NMDA receptor-mediated synaptic response. Raw fEPSP slopes are shown on the left. The curves on the right are normalized to fEPSP slope in the presence of the mixture and show that the remaining fEPSP is eliminated by $50 \mu \mathrm{mAP}$. This confirms that the EPSP in the presence of the mixture is NMDA receptor mediated. D, UBP304 $(3 \mu \mathrm{m})$ but not UBP308 $(3 \mu \mathrm{M})$ antagonizes the depressant effect of ATPA $(3 \mu \mathrm{M})$ on monosynaptically evoked IPSPs. Single representative experiments $(\boldsymbol{A}-\boldsymbol{D}$, left) are accompanied by numbered traces (average, 4 successive points). Normalized data from all experiments are presented at right in $\boldsymbol{B}-\boldsymbol{D}(n=4,3$, and 4 , respectively). Calibration: $\boldsymbol{A}, 1 \mathrm{mV}, 25 \mathrm{~ms} ; \boldsymbol{B}, 0.5 \mathrm{mV}, 25 \mathrm{~ms} ; \boldsymbol{C}, 0.5 \mathrm{mV}, 500 \mathrm{~ms} ; \boldsymbol{D}, 5 \mathrm{mV}, 100 \mathrm{~ms}$.

dence that UBP304-induced decreases of theta frequency are not a result of reduced locomotor speed. To this end, we selected only those intervals during which the running speed was between 20 and $30 \mathrm{~cm} / \mathrm{s}$ and asked whether post-UBP304 theta frequency was 
A
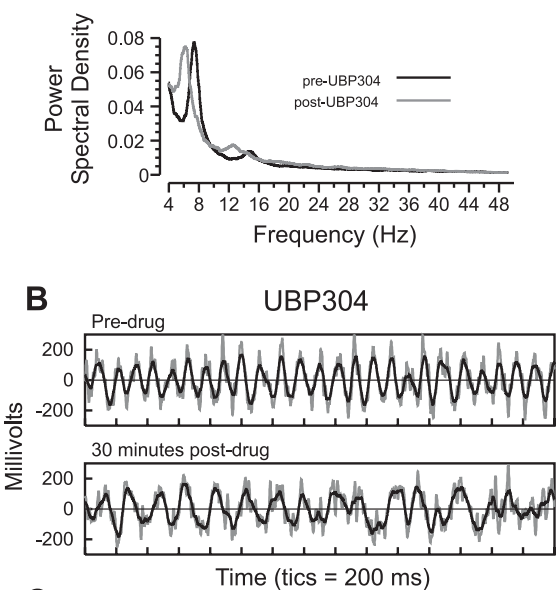

C

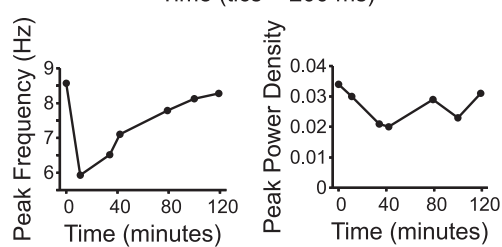

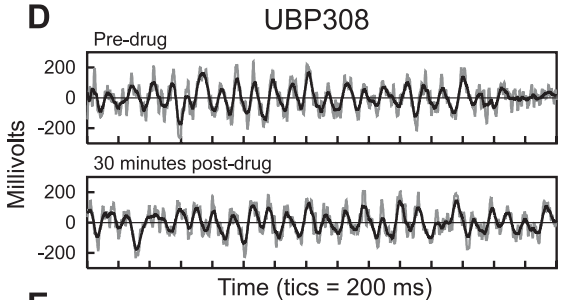

E

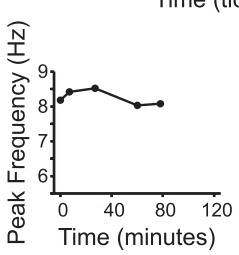

Figure 2. The frequency of the theta rhythm of the hippocampal EEG is slowed by inhibition of GLU $\mathrm{K}_{5}$ receptors. $A$, A representative power spectral density plot before (black) and $30 \mathrm{~min}$ after (gray) administration of UBP304, showing the distinct peak in the theta frequency band. Note the $\sim 1.5 \mathrm{~Hz}$ reduction in theta frequency after the drug. The smaller peak in each line is the higher frequency theta harmonic. The analysis was based on analysis at 1024 frequency values between 0 and $50 \mathrm{~Hz}$, and the resultant plot was smoothed with a 20 sample sliding window. $\boldsymbol{B}$, Three second EEG traces before (top) and 30 min after (bottom) intracerebroventricular injection of UBP304. The gray traces show the raw EEG; the black traces are after smoothing (see Materials and Methods). Both recordings were made during walking episodes. Counting peaks is sufficient to show that the theta frequency is slower in the postdrug record; in contrast, theta amplitude seems virtually unchanged. C, Time course of the effects of UBP304 on theta frequency (left) and power (right) in a single rat. Measurements at time "zero" are predrug. The frequency reduction is greatest 10 min after injection and gradually diminishes; no major changes are seen in peak theta power. $\boldsymbol{D}$, Three second EEG traces before and after treatment with UBP308, the inactive drug form. Neither theta frequency nor amplitude is affected $30 \mathrm{~min}$ after injection. $\boldsymbol{E}$, Results from a different rat showing the time course of the effects of UBP308. The constancy of theta frequency (left) and power (right) reflect the inert nature of UBP308.

nevertheless lower than pre-UBP304 frequency. The comparison was made between predrug sessions and sessions done $30 \mathrm{~min}$ postinjection, because the full range of running speeds was seen after this delay. From Figure $3 G$, it is evident that UBP304 caused a strong decrease of theta frequency $(1.19 \mathrm{~Hz})$ even after speed clamping, whereas little frequency change $(0.03 \mathrm{~Hz})$ was caused by UBP308. This conclusion was tested with a repeated-measure ANOVA

of CA1 theta frequency for predrug and postdrug for the two drugs. The ANOVA found a strong pre/postdrug effect $\left(F_{(1,15)}=21.19 ; p<0.001\right)$ but no direct effect of drug $\left(F_{(1,15)}=\right.$ $1.85 ; p=0.19)$. The lack of a drug effect is a consequence of the nearly invariant peak theta frequency before $(7.85 \mathrm{~Hz})$ and after $(7.81 \mathrm{~Hz})$ UBP308 coupled with the fact that peak theta frequency for the UBP304 sample was higher before drug $(8.09 \mathrm{~Hz})$ but much lower after drug $(6.98 \mathrm{~Hz})$ than the corresponding UBP308 values; the mean frequencies for the two drugs therefore did not differ. Nevertheless, as expected from the main effects, there was a very strong pre/post by drug interaction $\left(F_{(1,15)}=18.85 ; p<\right.$ $0.001)$. Thus, paired $t$ tests revealed a significant reduction in theta frequency after UBP304 $\left(t_{(1,10)}=-7.14 ; p<0.0001\right)$ but not UBP308 $\left(t_{(1,5)}=-0.18 ; p=0.86\right)$. There was no pre-post difference in theta power $\left(F_{(1,15)}=0.62 ; p=0.45\right)$, nor was there any interaction with the drug used $\left(F_{(1,15)}=0.01 ; p=0.93\right)$. For both drugs, theta power was approximately as likely to increase after injection as it was to decrease. We conclude that the ability

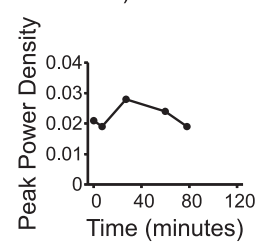

of kainate receptor blockade to reduce theta frequency is not a result of slowed locomotion and that UBP304 has no effect on theta power.

Although any effect of running speed on theta frequency within the $20-30 \mathrm{~cm} / \mathrm{s}$ window would be miniscule, it is possible that the effect is unique to this running speed range or that a more important effect is being masked by averaging within this window. To eliminate this explanation, we further broke the data down into 2 $\mathrm{cm} / \mathrm{s}$ speed bins (from 10 to $40 \mathrm{~cm} / \mathrm{s}$ ) to see whether the effect was still present. The consistent reduction of theta frequency at all $2 \mathrm{~cm} / \mathrm{s}$ running speed bins is presented in Figure $3 \mathrm{H}$, strongly reinforcing the conclusion that UBP304 reduces theta frequency independent of effects on running speed.

We also confirmed with an ANOVA that UBP304 reduced theta frequency in both the random foraging and circular track tasks. There was a robust effect of UBP304 $\left(F_{(1,9)}=51.48 ; p<0.0001\right)$ but no task effect $\left(F_{(1,9)}=0.42 ; p=0.53\right)$ nor a UBP304 by task interaction $\left(F_{(1,9)}=\right.$ $1.50 ; p=0.25)$. Moreover, paired $t$ tests revealed significant reductions in theta frequency of $17 \%$ for random foraging $\left(t_{(1,5)}=-5.18 ; p<0.01\right)$ and of $11 \%$ for the circular track $\left(t_{(1,4)}=-4.46 ; p<\right.$ 0.05). A separate, parallel ANOVA for UBP308 revealed no significant effects of $\operatorname{drug}\left(F_{(1,4)}=0.71 ; p=0.45\right), \operatorname{task}\left(F_{(1,4)}\right.$ $=5.91 ; p=0.07)$, nor the UBP308 by task interaction $\left(F_{(1,4)}=3.55 ; p=0.13\right)$. Based on these considerations, data from the two tasks were combined for all other analyses.

\section{UBP304-induced reduction of theta frequency is the same in all cell layers}

Simultaneous EEG recordings in DG, CA3, and CA1 revealed that UBP304 causes the same decrease in theta frequency $30 \mathrm{~min}$ after drug in all three areas (Fig. 4A, left), whereas UBP308 has no effect (Fig. $4 A$, right). There was a small trend for postinjection theta power in all areas to be reduced, regardless of whether UBP304 or UBP308 was administered (Fig. 4 B). Power was lower in CA1 than in DG or CA3 both before and after injection.

These impressions of frequency and amplitude effects were tested separately for both drugs with repeated-measures ANOVA using cell layer as the between-subjects variable. There was a strong tendency for theta frequency to drop because of $\mathrm{GLU}_{\mathrm{K} 5}$ blockade $\left(F_{(1,19)}=41.77 ; p<0.0001\right)$ but no cell layer interaction with drug state $\left(F_{(2,19)}=0.51 ; p=0.61\right)$. As expected, UBP308 did not affect frequency $\left(F_{(1,11)}=00.02 ; p=0.89\right)$ and there was no cell layer interaction with drug state $\left(F_{(2,11)}=0.14 ; p=0.87\right)$. Similar ANOVAs for theta power reveal no overall change attributable to $\operatorname{UBP} 304\left(F_{(1,19)}=1.38 ; p=0.25\right)$, but a small although statistically significant decrease for UBP308 $\left(F_{(1,11)}=6.18 ; p<\right.$ $0.05)$. Given the trend for a reduction in theta power even after aCSF injections (Fig. 3B) and the lack of in vivo effects of UBP304 on AMPA, NMDA, and $\mathrm{GLU}_{\mathrm{K} 5}$ receptors, the weak power reduc- 

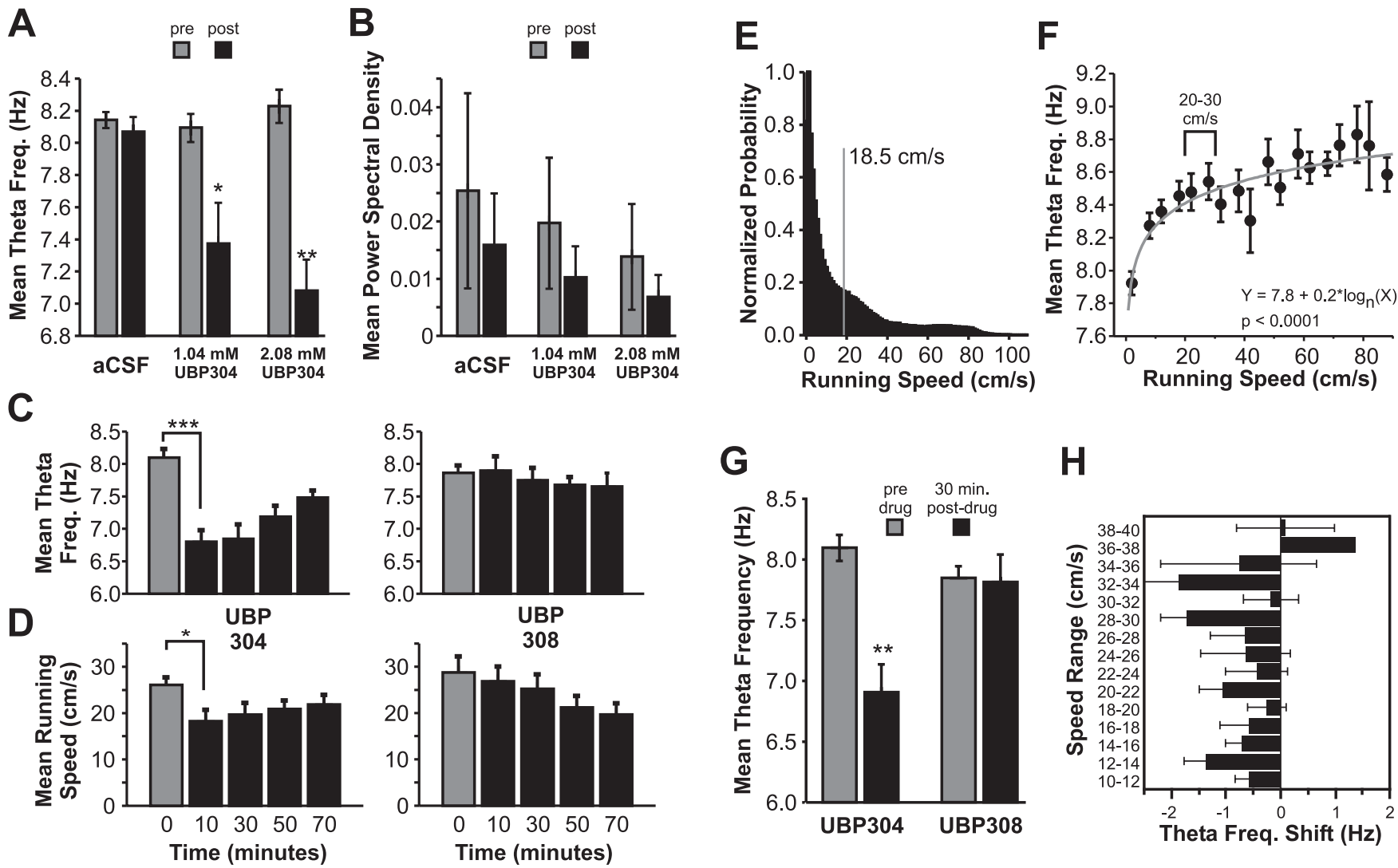

Figure 3. Drug effects on running speed and theta frequency are independent. $A$, Four rats were given injections of UBP304 at the original dose (2.08 mM), half-dose (1.04 mM), and "zero" dose (aCSF vehicle). The drop in theta frequency exhibits dose dependence, with no significant reduction after aCSF. $\boldsymbol{B}$, Theta power in the same four rats shows no significant reduction and no dose-response relationship. $\boldsymbol{C}, \boldsymbol{D}$, Between-subjects average theta frequency $(\boldsymbol{C})$ and running speed $(\boldsymbol{D})$ are plotted as a function of time. UBP304 (left) causes reductions in theta frequency and running speed that are similar in time course but different in magnitude. UBP308 (right) has no effect on theta frequency, but running speed is seen to decrease progressively during repeated sessions, an effect associated with time in the apparatus commonly seen in the absence of drug administration. Note that running speed is nearly the same during the last UBP304 and UBP308 sessions. $\boldsymbol{E}$, Running speed histogram (predrug trials) for all rats combined. The peak near zero represents immobility, small head motion and direction changes, whereas the inflection near $20 \mathrm{~cm} / \mathrm{s}$ is characteristic of walking during foraging. Gray line, Mean running speed. $\boldsymbol{F}$, The relationship between predrug running speed and theta frequency is well fit by logarithmic function. Data were filtered for running speed in $5 \mathrm{~cm} / \mathrm{s}$ windows. Mean theta frequency was calculated for each rat in each window. Gray line, Best fit, Regression equation at bottom right. $G$, Restricting running speed to a narrow range (speed clamping) does not affect theta frequency reduction attributable to antagonism of $\mathrm{GLU}_{\mathrm{K} 5}$ receptors. EEG samples were selected only for intervals during which rats ran between 20 and $30 \mathrm{~cm} / \mathrm{s}$. Theta frequency is shown for UBP304 and UBP308 before drug (gray bars) and 30 min after drug (black bars). $\boldsymbol{H}$, The change in theta frequency after UBP304 is also consistently negative across a large range of very restrictive $(2 \mathrm{~cm} / \mathrm{s})$ speed-clamping windows. For all plots, error bars are SEM. ${ }^{* *} p<0.01$. Where restrictive selection of data produced small sample sizes $(\boldsymbol{F}, \boldsymbol{H})$, mean theta frequency was taken as the inverse of the mean duration of detected theta cycles.

tion after UBP308 is likely nonpharmacological or a statistical accident; it will not be considered further.

We also asked how theta peak frequency and amplitude varied across layers on combined predrug trials. No frequency differences were seen (CA1, $8.09 \mathrm{~Hz}$; CA3, $8.02 \mathrm{~Hz}$; DG, $7.68 \mathrm{~Hz}$; $\left.F_{(2,19)}=0.69 ; p=0.51\right)$. In contrast, there were significant differences in theta power $\left(F_{(2,19)}=5.27 ; p<0.05\right)$. Pairwise comparisons using Tukey-Kramer's honestly significant difference revealed that power was about twice as high in CA3 [least significant difference (LSD), 0.022; CA3-CA1, 0.037; $p<0.001]$ and the upper blade of DG than in CA1 (LSD, 0.019; DG-CA1, 0.033; $p<0.001)$, but there was no significant difference between CA3 and DG (LSD, 0.024; CA3-DG, 0.005; $p>0.80$ ). These results are consistent with previously published observations (Buzsaki et al., 1986; Bragin et al., 1995).

\section{The effects of UBP304 on the activity of principal} hippocampal cells

Recordings were made from 110 well isolated neurons, 90 of which were classified as principal cells (pyramidal cells or granule cells) and 13 of which were classified as interneurons; the remaining 7 cells did not fit our criteria for either main type and were excluded from the analysis. Of the principal cells, 54 were CA1 pyramidal cells, 11 were CA3 pyramidal cells, 18 were putative DG granule cells, and 7 were putative polymorph layer mossy cells. A detailed breakdown of the classified cell types and the layers they were recorded from is presented in Table 1.

Examples of how UBP304 affected the spatial distribution of principal cell firing are shown in Figure 5. Each row illustrates, for a single unit, recordings during a predrug control period (left column), 30 min after injection (middle column), and $\sim 1 \mathrm{~h}$ after injection (right column). Three general features should be noted as follows: (1) The crispness of the spatial firing pattern during the $30 \mathrm{~min}$ postdrug session is reduced in all cases. This observation corresponds to a decrease of spatial coherence as shown below. (2) The overall firing pattern is preserved for each cell; for even the most affected units (cells 5 and 6), residual discharge continues to occur in the vicinity of the original firing field. (3) By $1 \mathrm{~h}$ after drug injection, a great deal of recovery has occurred; this corresponds to an increase of coherence compared with the 30 


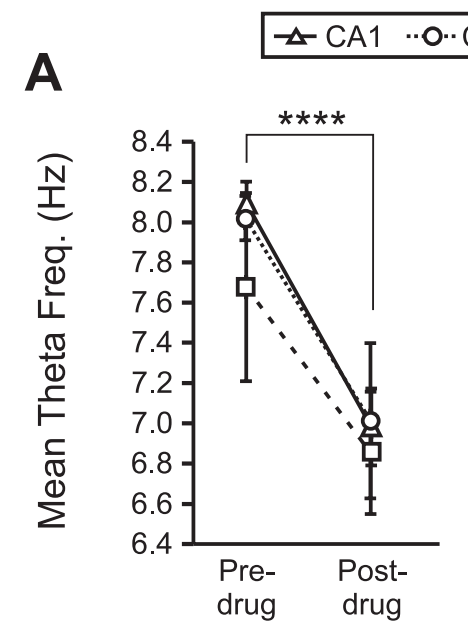

UBP304

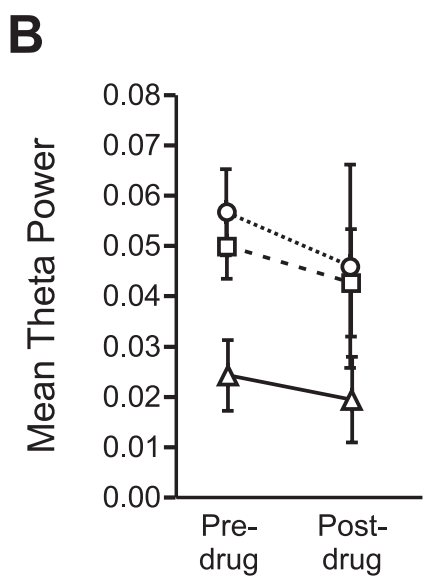

UBP304

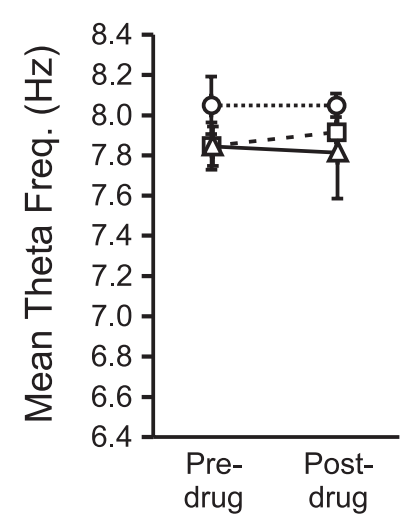

UBP308

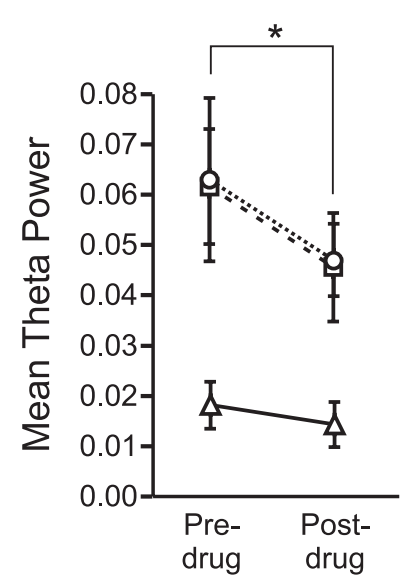

UBP308

Figure 4. The effects of $\mathrm{GLU}_{\mathrm{K} 5}$ antagonism are similar in all recorded hippocampal cell layers. Measures are taken only during speed-clamping from $20-30 \mathrm{~cm} / \mathrm{s}$. $\boldsymbol{A}$, Theta frequency diminishes between a predrug session and a 30 min postdrug session in CA1, CA3, and dentate gyrus after UBP304 (left; $n=11,4$, and 7, respectively) but is constant after UBP308 (right; $n=6,3$, and 5 , respectively). $\boldsymbol{B}$, Theta power shows small decreases in the postdrug session; these are not reliable after UBP304 but are marginally significant after UBP308. ${ }^{*} p<0.05 ;{ }^{* * * *} p<$ 0.0001 .

Table 1. Summary of the type and location of single-cell recordings

\begin{tabular}{lrrrllr}
\hline Cell type & CA1 & CA3 & DG & Polymorph & Alveus/oriens & Total \\
\hline Principal cells & 54 & 11 & 18 & 7 & 0 & 90 \\
Theta cells (interneurons) & 5 & 0 & 1 & 0 & 0 & 6 \\
Other interneurons & 3 & 0 & 1 & 1 & 2 & 7 \\
Total & 62 & 11 & 20 & 8 & 2 & 103 \\
\hline
\end{tabular}

min session. These effects are seen in cells from CA1, CA3, DG, and the PM layer. By inspection of rate maps, injection of UBP308 did not alter principal cell activity (data not shown).

Numerical analysis of the effects of UBP304 was first done for the spatial firing patterns of CA1 pyramidal cells, because these are presumed to form a homogeneous group. For this analysis, the number of cells was limited to 38 by the requirement that a cell was recorded during a predrug and a $30 \mathrm{~min}$ postdrug session. According to paired $t$ tests, the overall rate of 1.01 spikes/s in the predrug session and of 0.903 spikes/s in the postdrug session were

\section{Pre $\quad 30 \mathrm{~min}>50 \mathrm{~min}$}
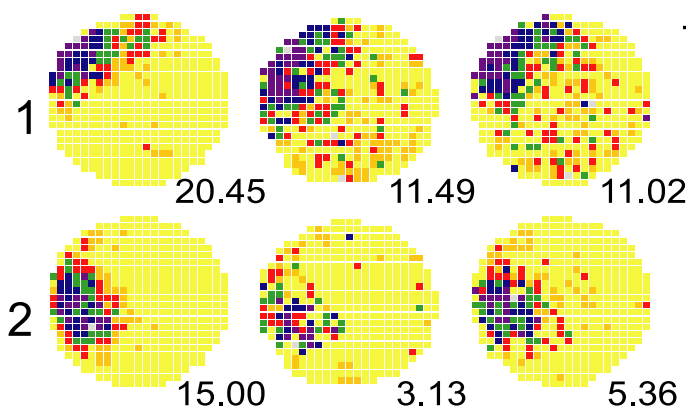

15.00
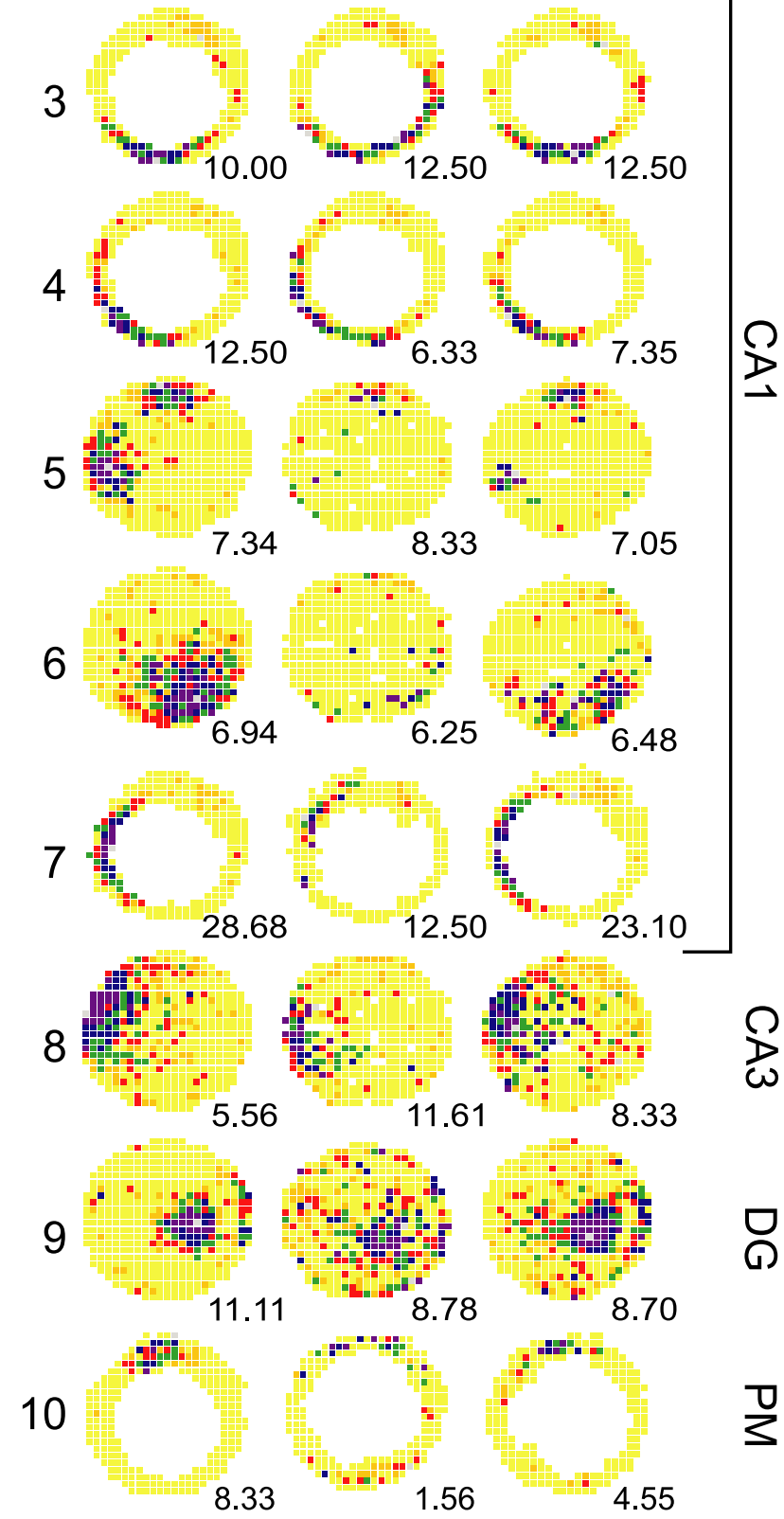

Figure 5. Disruption of place cell firing fields by $\mathrm{GLU}_{\mathrm{K} 5}$ blockade. In these representative examples, each row shows a firing rate map for a single cell before, 30 min after, and $>50 \mathrm{~min}$ after administration of UBP304. Note that, 30 min after UBP304 injection, cell firing is more scattered, with varying degrees of recovery beyond $50 \mathrm{~min}$. The layer of the cell is indicated as CA1, CA3, DG, or PM. Annular rate maps indicate the recording was made on a circular track. Yellow pixels represent regions in which the cell fired no spikes. Darker colors represent higher firing rates, autoscaled to the peak rate for each cell. Median values for purple pixels (peak firing rate) are given under each map. 
A
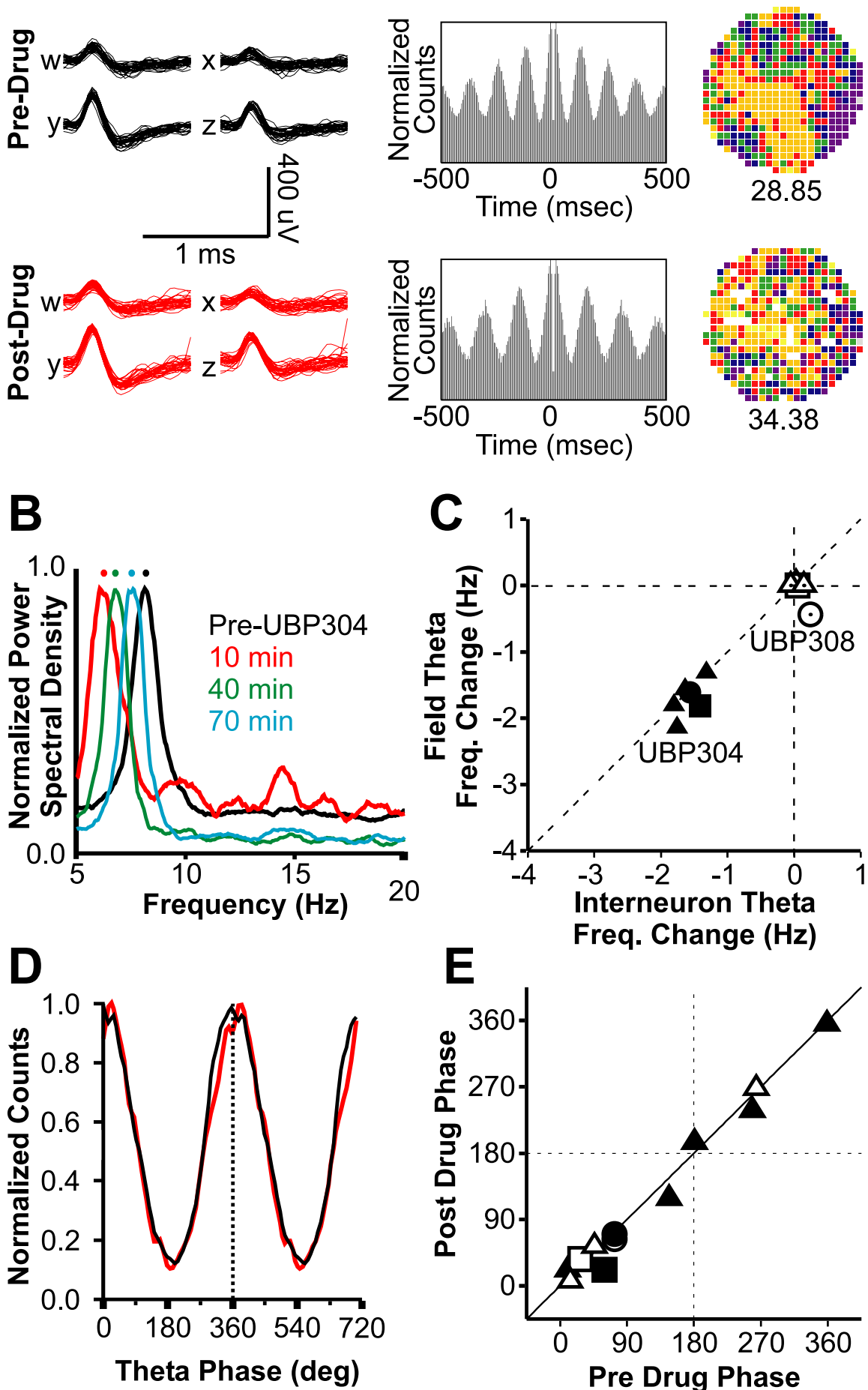

Figure 6. Effects of blocking $\mathrm{GLU}_{\mathrm{K} 5}$ receptors on the activity of interneurons recorded before (top row) and 30 min after (bottom row) administration of UBP304. $\boldsymbol{A}$, Tetrode waveforms ( $w-z$, left) were unaffected by UBP304. Spike autocorrelations (middle) show that UBP304 reduced the frequency of theta-modulated discharge; this is detectable simply by counting the number of peaks before and after UBP304. Firing rate maps (right) show that spatial organization of discharge is reduced by UBP304; the median rate in the peak (purple) category is shown below each map. $\boldsymbol{B}$, The time course of frequency change of theta-modulated firing matches the time course of the frequency change of theta itself; data are for the same cell as in $\boldsymbol{A}$. The curves show the normalized CA1 EEG power spectrum for sessions before (black), $10 \mathrm{~min}$ after (red), $40 \mathrm{~min}$ after (green), and 70 min after (blue) administration of UBP304. Frequency obtained from the peak of the spike autocorrelation is plotted in the same colors above the power spectra, from which it is clear that the EEG and single-unit frequencies changed in parallel. C, Cross-cell comparison of the theta-modulated frequency shift of interneuron firing with the theta frequency shift in simultaneously recorded CA1 EEG. Shifts are frequencies 30 min postdrug measures minus predrug frequencies. Symbols represent the layer of the cell: CA1 (triangles), dentate gyrus (squares), and polymorph layer (circles). UBP304 (filled symbols) causes equal shifts in each measure of frequency; UBP308 (open symbols) affects neither. $\boldsymbol{D}$, Phase histograms for an interneuron before (black) and $30 \mathrm{~min}$ after (red) not reliably different $(t=0.78$; $\mathrm{df}=37$; $p=0.44)$. Similarly, the predrug $(2.27$ bits/spike) and postdrug (2.43 bits/spike) values of information content were not significantly different $(t=0.34 ; \mathrm{df}=37$; $p=0.98)$. The apparent lack of effect on overall rate is despite the rather large changes for many individual cells and may be because rate increases were about as common as rate decreases. Within the place field of each cell, there was a small decrease in rate from 3.21 to 2.58 spikes/s $(t=2.51 ; \mathrm{df}=37 ; p<0.05)$ that would not contribute by itself very much to the altered appearance of spatial firing patterns. In contrast, two other changes, namely, field size and coherence, strongly impacted the appearance of rate maps; field size decreased from 74.1 to 53.6 pixels $(t=3.11 ; \mathrm{df}=37 ; p<0.01)$ and coherence from 1.16 to $0.746(t=5.13$; $\mathrm{df}=37 ; p<$ 0.0001 ). Thus, discharge was on the average less dense and more poorly organized.

The pattern of UBP304-induced changes for principal cells outside CA1 was much the same, although the decrease of peak rate from 7.07 spikes/s to 5.32 was associated with too much variance to be significant (paired $t=1.10$; df $=19 ; p=$ 0.29 ). When we took advantage of the similarity of UBP304-induced effects on CA1 and other principal cells, statistical differences of peak rate $(t=2.73 ; p<0.01 ; \mathrm{df}=$ $57)$, field size $(t=4.08 ; p<0.001$; df $=$ 57 ), and coherence $(t=5.99 ; p<0.0001$; $\mathrm{df}=57)$ were magnified. We conclude that UBP304 similarly degrades the spatial firing patterns of principal cells in all layers of the hippocampus. In contrast, no systematic changes in principal cell firing were induced by UBP308 (data not shown).

The effects of UBP304 on interneurons Recordings were made from 13 well isolated neurons classified as putative interneurons. Of these, six were "classic" theta cells that fired rapidly everywhere in the environment. Theta cell discharge was strongly modulated by the theta rhythm with a clear tendency to fire most rapidly at a particular theta phase. We focus on

administration of UBP304; data are for the same cell as in $\boldsymbol{A}$. The vertical line at $0^{\circ}$ marks the zero crossing of the descending phase of theta in the CA1 EEG. Note that the phase histogram is hardly changed despite the large change in frequency. $\boldsymbol{E}$, Cross-cell demonstration of invariance of firing phase of six interneurons relative to CA1 theta. Symbol shapes are for different layers, as in C. Filled symbols are for UBP304; open symbols are for UBP308. Phase invariance is indicated by the $45^{\circ}$ line. 
UBP304-induced changes in theta cell activity, because the remaining seven cells did not fall clearly into only one or two classes, and as a result it is hard to summarize their properties.

An example of how UBP304 altered theta cell discharge is shown in Figure $6 A-C$. The left part of Figure $6 A$ demonstrates that the waveform is constant on all wires of the tetrode before (black) and after (red) the UBP304 injection. However, the RFF of interneurons was significantly slowed. The autocorrelograms of cell discharge (Fig. 6A, middle) show that the predrug RFF of $\sim 8 \mathrm{~Hz}$ (top) is slowed by UBP304 to $\sim 6.2 \mathrm{~Hz}$ (bottom), parallel to the UBP304-induced reduction of the EEG. Figure $6 \mathrm{~A}$, right, shows firing rate maps for the predrug (top) and postdrug (bottom) sessions. The predrug map is typical of a theta cell (Kubie et al., 1990); the cell discharges everywhere in the environment (note the absence of zero-rate, yellow pixels) with rather large areas of relatively low (orange-coded) and relatively fast (purple/ blue) firing. The postdrug rate map bears a strong resemblance to the predrug map, although it is noisier and less well organized, despite the small increase in firing rate. As expected from the less organized rate map after UBP304, the coherence for this cell decreased from 1.83 to 1.43 .

When the power spectra of the discharge of this theta cell and of the simultaneously measured CA1 EEG are computed, the peak frequencies are very tightly related. This holds true before administration of UBP304, at the time of the greatest drug action and during return to the predrug state, as shown for four recording sessions in Figure $6 \mathrm{~B}$. It can be seen from Figure $6 C$ that the near equality of UBP304-induced changes in RFF and the dominant frequency of the EEG is characteristic of the whole theta cell sample. Note that UBP308 caused no change in the RFF of interneurons, nor in the dominant EEG frequency.

If theta cell discharge is rhythmic at the dominant EEG frequency, how is the phase relationship between spikes and the EEG cycle altered by UBP304? Normalized phase histograms for the example cell are shown in Figure $6 D$, for both the predrug session (black trace) and the postdrug session (red trace). The near identity of the histograms suggests that UBP304 hardly affects the relative excitability of this interneuron over the cycle even as theta frequency diminishes. The constancy of the EEG phase for peak theta cell discharge holds for the entire sample, as seen in Figure $6 E$.

Statistical calculations reinforce impressions from graphical presentation. Thus, a mixed design ANOVA revealed a robust predrug versus postdrug effect on $\operatorname{RFF}\left(F_{(1,5)}=39.43 ; p<0.005\right)$, and a significant pre/post by drug interaction $\left(F_{(1,5)}=47.32 ; p<\right.$ $0.005)$. Paired $t$ tests revealed that the reduction in RFF from 8.45 to $7.02 \mathrm{~Hz}$ after UBP304 was significant $(t=-7.89 ; p<0.005$; $\mathrm{df}=3$ ). In contrast, UBP308 had no effect on theta frequency (mean difference, $0.07 \mathrm{~Hz} ;=1.51 ; p=0.27 ; \mathrm{df}=2$ ). As shown in Figure $6 C$, there was a strong positive correlation between changes of interneuron RFF and changes in the frequency of simultaneously recorded CA1 theta EEG $\left(R^{2}=0.997 ; F_{(1,4)}=\right.$ $1474.26 ; p<0.0001)$. This effect is mainly attributable to differences between the UBP304 and UBP308 datasets. Therefore, we next considered only the three (of six) theta cells with unambiguous field and cell firing rhythmicity after administration of UBP304. For each cell, changes in the frequency of rhythmic firing/field theta were as follows (in $\mathrm{Hz}$ ): $-1.81 /-1.80,-1.61 /$ -1.61 , and $-1.32 /-1.31$. Despite the small sample size for this cell class, the correlation between changes in field theta and RFF is pronounced. The drugs did not significantly reduce the overall firing rate of interneurons (pre, $28.82 \mathrm{~Hz}$; post, $26.40 \mathrm{~Hz} ; F_{(1,5)}=$
2.54; $p=0.17)$, and there was no interaction between drug state and drug type $\left(F_{(1,5)}=0.25 ; p=0.64\right)$.

\section{Discussion}

Our results represent the first characterization of the effects of inhibiting a kainate receptor subclass on cell firing and theta oscillations in awake, freely moving animals. Antagonism of kainate receptors containing the $\mathrm{GLU}_{\mathrm{K} 5}$ subunit slows the frequency of hippocampal theta in a dose-dependent manner but has little effect on theta amplitude. In addition, place field coherence and the RFF of putative interneurons were reduced in the absence of strong effects on mean firing rates. The effects are reversible, independent of changes in behavior and specific to the $S$-enantiomer form of the drug.

\section{$\mathrm{UBP} 304$ acts preferentially on $\mathrm{GLU}_{\mathrm{K} 5}$ receptors}

Until recently, it has been difficult to distinguish pharmacologically between kainate and AMPA receptors, or between receptors containing $\mathrm{GLU}_{\mathrm{K} 5}, \mathrm{GLU}_{\mathrm{K} 6}$, and $\mathrm{GLU}_{\mathrm{K} 7}$ subunits. However, experiments using cloned cells and isolated dorsal root fibers (Dolman et al., 2006) and hippocampal slices (the present study) indicate that UBP304 is a potent, selective antagonist of $\mathrm{GLU}_{\mathrm{K}_{5}}{ }^{-}$ containing kainate receptors; it only weakly blocks AMPA receptors and has no detectable effect on NMDA receptors or receptors containing other kainate subunits. In hippocampal slices, UBP304 had an $\mathrm{IC}_{50}$ of $37 \mu \mathrm{M}$ for antagonizing AMPAmediated transmission, whereas $\mathrm{GLU}_{\mathrm{K} 5}$-mediated effects were fully blocked at only 3.0 $\mu \mathrm{M}$. Assuming whole-brain dilution, our UBP304 injection would produce a brain concentration of $\sim 4.0$ $\mu \mathrm{M}$, about an order of magnitude below the $\mathrm{IC}_{50}$ for AMPA receptors. We could not measure the brain drug concentration and so cannot rule out possible UBP304 effects at unintended receptor targets. However, a recent study showed that local or ventricular injections of the AMPA blockers DNQX or CNQX in behaving rats reduces the amplitude of hippocampal theta oscillations at doses that had no effect on theta frequency (Leung and Shen, 2004). This is in marked contrast to the ability of UBP304 to slow theta frequency without affecting its amplitude and strongly suggests we are not blocking AMPA receptors. Interestingly, Leung and Shen also found that high doses of DNQX $(10 \mu \mathrm{g})$ slowed theta. Because DNQX binds to kainate receptors with low affinity (Lerma et al., 2001), this frequency effect may be attributable to blockade of $\mathrm{GLU}_{\mathrm{K} 5}$ receptors.

\section{$\mathrm{GLU}_{\mathrm{K} 5}$ receptors modulate the frequency of the hippocampal theta rhythm}

The slowing of the theta by UBP304 appears to be a direct neural effect and not an indirect consequence of decreased running speed. First, we characterized the relationship between speed and theta frequency on baseline trials and found that speed changes produced by UBP304 could not account for the magnitude of the reduction in theta frequency. Second, we selected intervals during which running occurred in a narrow speed range (20-30 $\mathrm{cm} / \mathrm{s}$ ) and reanalyzed theta frequency only for such intervals. The drop of theta frequency after speed-clamping is strong evidence that the effect of UBP304 on theta is not secondary to behavioral changes.

UBP304 slows theta frequency equally in all hippocampal subfields. This may be attributable to a common mechanism involving $\mathrm{GLU}_{\mathrm{K} 5}$ receptors in each region or to a frequency change in a critical "pacemaker" region that propagates throughout the hippocampus. $\mathrm{GLU}_{\mathrm{K} 5} \mathrm{mRNA}$ is highly expressed perinatally in CA1 stratum oriens and the septum (Bahn et al., 1994) and in pontine 
nuclei, which project to MS-DBB (Wisden and Seeburg, 1993); these nuclei play an important role in generating MS-DBBmediated theta oscillations (Kirk, 1998; Kinney et al., 1999). Identifying the critical locus of UBP304 action will require local injection of $\mathrm{GLU}_{\mathrm{K} 5}$ antagonists into each region and is a focus of future experiments.

\section{Mean cell firing rates and preferred theta phase were unaltered by $\mathrm{GLU}_{\mathrm{K} 5}$ receptor blockade}

UBP304 induced no change in the mean firing rate of CA1 stratum pyramidale interneurons at running speeds $>5 \mathrm{~cm} / \mathrm{s}$ despite a drop in RFF. Thus, the $\sim 125 \mathrm{~ms}$ interval between theta phaselocked firing lengthened, but the same number of spikes occurred over longer timescales. In previous work in hippocampal slices, the $\mathrm{GLU}_{\mathrm{K} 5}$-selective agonist ATPA raised the firing rate of several classes of hippocampal interneurons after excitatory synaptic transmission was blocked, (Cossart et al., 1998). One might expect a $\mathrm{GLU}_{\mathrm{K} 5}$ antagonist to produce the opposite effect, but this is not what we observed. There are several possible explanations. (1) Our interneuron sample may not have expressed $\mathrm{GLU}_{\mathrm{K} 5}$ receptors but were entrained by others that did. (2) The relative contribution of $\mathrm{GLU}_{\mathrm{K} 5}$ receptors to tonic drive on our cells may be small compared with what is provided by AMPA and/or NMDA receptor-mediated excitatory transmission but nevertheless sufficient to affect their rhythmicity. (3) Network compensation may have masked the effects of UBP304 on overall firing rate while leaving rhythmic entrainment intact.

It is worth noting that using current injection to change the RFF of an inhibitory neuron can entrain the targets of the cell at the altered frequency (Elson et al., 2002). Therefore, the sign of changes in RFF need not reverse across inhibitory synapses, and RFF changes in any given class of neurons may propagate through an entire network, even one comprised of mutually inhibitory synapses (Wang and Rinzel, 1992). It is also worth noting that we saw no change in the preferred firing phase of interneurons, despite the reductions in RFF and theta field oscillation frequency. Although theta frequency did not drop as low as the $\sim 4 \mathrm{~Hz}$ caused by urethane anesthesia, the constancy of firing phase helps validate the classification of interneurons based on preferred theta phase during urethane anesthesia (Klausberger et al., 2003).

\section{A simple model of theta pacemaking}

Blockade of a specific receptor type leads to a clearcut change in a prominent brain rhythmicity and holds out the promise of a mechanistic interpretation. We showed that the presynaptic $\mathrm{GLU}_{\mathrm{K} 5}$-containing kainate receptors at excitatory synapses onto pyramidal neurons (Vignes et al., 1998) are sensitive to UBP304. However, there is no evidence that these receptors are activated physiologically, except in very young animals (Lauri et al., 2006). Therefore, although we cannot discount a role of these receptors in the modulation of theta frequency, we feel that $\mathrm{GLU}_{\mathrm{K}^{-}}$ containing kainate receptors on inhibitory interneurons are the more likely site of action of UBP304.

There is considerable evidence that theta oscillations are controlled by interneuron activity. GABAergic cells in MS-DBB play a prominent role in theta generation (Lee et al., 1994). Moreover, kainate induces a form of theta in the MS-DBB that is sensitive to diazepam (Garner et al., 2005), a drug that slows the time course of IPSPs. Several hippocampal interneuron types express $\mathrm{GLU}_{\mathrm{K} 5}$ receptor mRNA, especially (but not exclusively) in stratum oriens (Paternain et al., 2000), and respond to $\mathrm{GLU}_{\mathrm{K} 5}$ receptor activation (Cossart et al., 1998). Approximately $80 \%$ of CA1 and
CA3 neurons that express $\mathrm{GLU}_{\mathrm{K} 5}$ mRNA also stain positive for GAD (glutamic acid decarboxylase), typical of GABAergic interneurons (Paternain et al., 2000). And finally, even a single class of rhythmic firing CA1 interneuron (O-LM cells) is capable of producing matched-frequency field oscillations in CA1 slices (Gillies et al., 2002).

We propose that the RFF of one or more classes of interneurons in the hippocampus and/or the MS-DBB is controlled by excitatory drive via $\mathrm{GLU}_{\mathrm{K} 5}$ subunit-containing kainate receptors. This is consistent with previous work showing that CA1 interneuron RFF is related to the level of constant depolarization applied to the cell (Chapman and Lacaille, 1999). Antagonism of GLU $\mathrm{K}_{5}$ receptors by UBP304 reduces excitatory input to these neurons and consequently reduces RFF. Other neurons are entrained at the reduced RFF through the strong reciprocal connectivity among hippocampal interneurons, and between interneurons in the hippocampus and MS-DBB (Toth et al., 1993; Gulyas et al., 2003). Given this network architecture, our pacemaker interneurons could be hippocampal, septal, or both. However, the end result must be that entrainment includes those interneurons that directly provide rhythmic inhibitory input to pyramidal cell dendrites, which in turn gives rise to theta field oscillations of the same frequency.

\section{Implications for the cognitive map}

We observed degradation in the coherence of spatial firing patterns in place cells under $\mathrm{GLU}_{\mathrm{K} 5}$ receptor antagonism, despite preservation of their mean firing rate. This weakening of the ability of place cells to accurately signal position was observed even on trials when the rat's coverage of the environment was thorough and so cannot be explained in terms of poor spatial sampling. One possibility is that altering the rate of phasic inhibition to hippocampal principal cells changes the way they respond to excitatory input, increasing the action potential failure rate. For example, a decoupling of theta frequency inhibition from the intrinsic membrane potential oscillations in CA1 pyramidal cells may cause the failure of perforant path excitation to reach the soma at optimal times to produce cell firing. This kind of decoupling might be expected if the pacemaker neurons were no longer receiving accurate feedback from the pyramidal cells about their global levels of excitation. In a dual-oscillator model of the relationship between spike times and theta oscillations (O'Keefe and Recce, 1993; Lengyel et al., 2003), this would have serious implications for phase precession and, in turn, for plastic processes and the acquisition/recall of spatial information (Skaggs and McNaughton, 1996; Lisman, 1999).

\section{References}

Anderson WW, Collingridge GL (2001) The LTP Program: a data acquisition program for on-line analysis of long-term potentiation and other synaptic events. J Neurosci Methods 108:71-83.

Bahn S, Volk B, Wisden W (1994) Kainate receptor gene expression in the developing rat brain. J Neurosci 14:5525-5547.

Bragin A, Jando G, Nadasdy Z, Hetke J, Wise K, Buzsaki G (1995) Gamma $(40-100 \mathrm{~Hz})$ oscillation in the hippocampus of the behaving rat. J Neurosci 15:47-60.

Brankack J, Stewart M, Fox SE (1993) Current source density analysis of the hippocampal theta rhythm: associated sustained potentials and candidate synaptic generators. Brain Res 615:310-327.

Bullock TH, Buzsaki G, McClune MC (1990) Coherence of compound field potentials reveals discontinuities in the CA1-subiculum of the hippocampus in freely-moving rats. Neuroscience 38:609-619.

Buzsaki G (1989) Two-stage model of memory trace formation: a role for "noisy" brain states. Neuroscience 31:551-570.

Buzsaki G (2002) Theta oscillations in the hippocampus. Neuron $33: 325-340$. 
Buzsaki G, Czopf J, Kondakor I, Kellenyi L (1986) Laminar distribution of hippocampal rhythmic slow activity (RSA) in the behaving rat: currentsource density analysis, effects of urethane and atropine. Brain Res 365:125-137.

Chapman CA, Lacaille JC (1999) Cholinergic induction of theta-frequency oscillations in hippocampal inhibitory interneurons and pacing of pyramidal cell firing. J Neurosci 19:8637-8645.

Clarke VR, Collingridge GL (2002) Characterisation of the effects of ATPA, a GLU(K5) receptor selective agonist, on excitatory synaptic transmission in area CA1 of rat hippocampal slices. Neuropharmacology 42:889-902.

Clarke VR, Ballyk BA, Hoo KH, Mandelzys A, Pellizzari A, Bath CP, Thomas J, Sharpe EF, Davies CH, Ornstein PL, Schoepp DD, Kamboj RK, Collingridge GL, Lodge D, Bleakman D (1997) A hippocampal GluR5 kainate receptor regulating inhibitory synaptic transmission. Nature 389:599-603.

Coan EJ, Collingridge GL (1985) Magnesium ions block an N-methyl-Daspartate receptor-mediated component of synaptic transmission in rat hippocampus. Neurosci Lett 53:21-26.

Cole AE, Nicoll RA (1983) Acetylcholine mediates a slow synaptic potential in hippocampal pyramidal cells. Science 221:1299-1301.

Cossart R, Esclapez M, Hirsch JC, Bernard C, Ben-Ari Y (1998) GluR5 kainate receptor activation in interneurons increases tonic inhibition of pyramidal cells. Nat Neurosci 1:470-478.

Davies CH, Davies SN, Collingridge GL (1990) Paired-pulse depression of monosynaptic GABA-mediated inhibitory postsynaptic responses in rat hippocampus. J Physiol (Lond) 424:513-531.

Dolman NP, More JC, Alt A, Knauss JL, Troop HM, Bleakman D, Collingridge GL, Jane DE (2006) Structure-activity relationship studies on N3-substituted willardiine derivatives acting as AMPA or kainate receptor antagonists. J Med Chem 49:2579-2592.

Elson RC, Selverston AI, Abarbanel HD, Rabinovich MI (2002) Inhibitory synchronization of bursting in biological neurons: dependence on synaptic time constant. J Neurophysiol 88:1166-1176.

Fox SE, Wolfson S, Ranck Jr JB (1986) Hippocampal theta rhythm and the firing of neurons in walking and urethane anesthetized rats. Exp Brain Res 62:495-508.

Garner HL, Whittington MA, Henderson Z (2005) Induction by kainate of theta frequency rhythmic activity in the rat medial septum-diagonal band complex in vitro. J Physiol (Lond) 564:83-102.

Gillies MJ, Traub RD, LeBeau FE, Davies CH, Gloveli T, Buhl EH, Whittington MA (2002) A model of atropine-resistant theta oscillations in rat hippocampal area CA1. J Physiol (Lond) 543:779-793.

Gray CM, Maldonado PE, Wilson M, McNaughton B (1995) Tetrodes markedly improve the reliability and yield of multiple single-unit isolation from multi-unit recordings in cat striate cortex. J Neurosci Methods 63:43-54.

Gulyas AI, Hajos N, Katona I, Freund TF (2003) Interneurons are the local targets of hippocampal inhibitory cells which project to the medial septum. Eur J Neurosci 17:1861-1872.

Holsheimer J (1982) Generation of theta activity (RSA) in the cingulate cortex of the rat. Exp Brain Res 47:309-312.

Hu H, Vervaeke K, Strom JF (2002) Two forms of electrical resonance at theta frequencies, generated by $\mathrm{M}$-current, $\mathrm{h}$-current and persistent $\mathrm{Na}^{+}$ current in rat hippocampal pyramidal cells. J Physiol 545:783-805.

Huxter J, Burgess N, O'Keefe J (2003) Independent rate and temporal coding in hippocampal pyramidal cells. Nature 425:828-832.

Kinney GG, Patino P, Mermet-Bouvier Y, Starrett Jr JE, Gribkoff VK (1999) Cognition-enhancing drugs increase stimulated hippocampal theta rhythm amplitude in the urethane-anesthetized rat. J Pharmacol Exp Ther 291:99-106.

Kirk IJ (1998) Frequency modulation of hippocampal theta by the supramammillary nucleus, and other hypothalamo-hippocampal interactions: mechanisms and functional implications. Neurosci Biobehav Rev 22:291-302.

Klausberger T, Magill PJ, Marton LF, Roberts JD, Cobden PM, Buzsaki G, Somogyi P (2003) Brain-state- and cell-type-specific firing of hippocampal interneurons in vivo. Nature 421:844-848.

Kubie JL, Muller RU, Bostock E (1990) Spatial firing properties of hippocampal theta cells. J Neurosci 10:1110-1123.

Lauri SE, Vesikansa A, Segerstrale M, Collingridge GL, Isaac JT, Taira T (2006) Functional maturation of CAl synapses involves activity- dependent loss of tonic kainate receptor-mediated inhibition of glutamate release. Neuron 50:415-429.

Lee MG, Chrobak JJ, Sik A, Wiley RG, Buzsaki G (1994) Hippocampal theta activity following selective lesion of the septal cholinergic system. Neuroscience 62:1033-1047.

Lengyel M, Szatmary Z, Erdi P (2003) Dynamically detuned oscillations account for the coupled rate and temporal code of place cell firing. Hippocampus 13:700-714.

Lerma J, Paternain AV, Rodriguez-Moreno A, Lopez-Garcia JC (2001) Molecular physiology of kainate receptors. Physiol Rev 81:971-998.

Leung LS, Shen B (2004) Glutamatergic synaptic transmission participates in generating the hippocampal EEG. Hippocampus 14:510-525.

Lisman JE (1999) Relating hippocampal circuitry to function: recall of memory sequences by reciprocal dentate-CA3 interactions. Neuron 22:233-242.

Mitchell SJ, Ranck Jr JB (1980) Generation of theta rhythm in medial entorhinal cortex of freely moving rats. Brain Res 189:49-66.

More JC, Nistico R, Dolman NP, Clarke VR, Alt AJ, Ogden AM, Buelens FP, Troop HM, Kelland EE, Pilato F, Bleakman D, Bortolotto ZA, Collingridge GL, Jane DE (2004) Characterisation of UBP296: a novel, potent and selective kainate receptor antagonist. Neuropharmacology 47:46-64.

Muller RU, Kubie JL, Ranck Jr JB (1987) Spatial firing patterns of hippocampal complex-spike cells in a fixed environment. J Neurosci 7:1935-1950.

O’Keefe J, Recce ML (1993) Phase relationship between hippocampal place units and the EEG theta rhythm. Hippocampus 3:317-330.

Pare D, Collins DR (2000) Neuronal correlates of fear in the lateral amygdala: multiple extracellular recordings in conscious cats. J Neurosci 20:2701-2710.

Paternain AV, Herrera MT, Nieto MA, Lerma J (2000) GluR5 and GluR6 kainate receptor subunits coexist in hippocampal neurons and coassemble to form functional receptors. J Neurosci 20:196-205.

Petsche H, Stumpf C, Gogolak G (1962) The significance of the rabbit's septum as a relay station between the midbrain and the hippocampus. I. The control of hippocampus arousal activity by the septum cells. Electroencephalogr Clin Neurophysiol 14:202-211.

Pike FG, Goddard RS, Suckling JM, Ganter P, Kasthuri N, Paulsen O (2000) Distinct frequency preferences of different types of rat hippocampal neurones in response to oscillatory input currents. J Physiol (Lond) 529:205-213.

Rotenberg A, Mayford M, Hawkins RD, Kandel ER, Muller RU (1996) Mice expressing activated CaMKII lack low frequency LTP and do not form stable place cells in the CA1 region of the hippocampus. Cell 87:1351-1361.

Rotenberg A, Abel T, Hawkins RD, Kandel ER, Muller RU (2000) Parallel instabilities of long-term potentiation, place cells, and learning caused by decreased protein kinase A activity. J Neurosci 20:8096-8102.

Skaggs WE, McNaughton BL (1996) Replay of neuronal firing sequences in rat hippocampus during sleep following spatial experience. Science 271:1870-1873.

Skaggs WE, McNaughton BL, Gothard KM, Markus EJ (1993) An informationtheoretic approach to deciphering the hippocampal code. In: Advances in neural information processing systems (Hanson SJ, Cowan JD, Giles CL, eds), pp 1030-1037. San Mateo, CA: Morgan Kaufmann.

Toth K, Borhegyi Z, Freund TF (1993) Postsynaptic targets of GABAergic hippocampal neurons in the medial septum-diagonal band of broca complex. J Neurosci 13:3712-3724.

Traub RD, Miles R, Wong RK (1989) Model of the origin of rhythmic population oscillations in the hippocampal slice. Science 243:1319-1325.

Vanderwolf CH (1969) Hippocampal electrical activity and voluntary movement in the rat. Electroencephalogr Clin Neurophysiol 26:407-418.

Vignes M, Clarke VR, Parry MJ, Bleakman D, Lodge D, Ornstein PL, Collingridge GL (1998) The GluR5 subtype of kainate receptor regulates excitatory synaptic transmission in areas CA1 and CA3 of the rat hippocampus. Neuropharmacology 37:1269-1277.

Wang XJ, Rinzel J (1992) Alternating and synchronous rhythms in reciprocally inhibitory model neurons. Neural Comput 4:84-87.

Whishaw IQ, Vanderwolf CH (1971) Hippocampal EEG and behavior: effects of variation in body temperature and relation of EEG to vibrissae movement, swimming and shivering. Physiol Behav 6:391-397.

Wisden W, Seeburg PH (1993) A complex mosaic of high-affinity kainate receptors in rat brain. J Neurosci 13:3582-3598. 